\title{
EPIC $95^{\circ} \mathrm{W}$ Observations of the Eastern Pacific Atmospheric Boundary Layer from the Cold Tongue to the ITCZ
}

\author{
Simon P. de Szoeke And Christopher S. Bretherton \\ Department of Atmospheric Sciences, University of Washington, Seattle, Washington \\ Nicholas A. Bond and Meghan F. Cronin \\ National Oceanic and Atmospheric Administration/Pacific Marine Environmental Laboratory, Seattle, Washington \\ BRUCE M. MORLEY \\ National Center for Atmospheric Research, Boulder, Colorado
}

(Manuscript received 13 February 2004, in final form 26 July 2004)

\begin{abstract}
The atmospheric boundary layer (ABL) along $95^{\circ} \mathrm{W}$ in the eastern equatorial Pacific during boreal autumn is described using data from the East Pacific Investigation of Climate (EPIC) 2001, with an emphasis on the evolution of the thermodynamic ABL properties from the cold tongue to the coldadvection region north of the sea surface temperature (SST) front. Surface sensible and latent heat fluxes and wind stresses between $1^{\circ} \mathrm{S}$ and $12^{\circ} \mathrm{N}$ are calculated from data from eight NCAR C-130 research aircraft flights and from Tropical Atmosphere Ocean (TAO) buoys. Reduced surface wind speed and a $10 \mathrm{~m} \mathrm{~s}^{-1}$ jet at a height of $500 \mathrm{~m}$ are found over the equatorial cold tongue, demonstrating the dependence of the surface wind speed on surface stability.

The ABL exhibits a maximum in cloud cover on the north (downwind) side of the warm SST front, at $1^{\circ}-3^{\circ} \mathrm{N}$. Turbulent mixing driven by both surface buoyancy flux and radiative cooling at the cloud tops plays a significant role in maintaining the depth and structure of the ABL. The ABL heat budget between the equator and $3^{\circ} \mathrm{N}$ is balanced by comparable contributions from advective cooling, radiative cooling, surface warming, and entrainment warming. Entrainment drying is a weak contributor to the moisture budget, relative to dry advection and surface evaporation. Both the heat and moisture budgets are consistent with a rapid entrainment rate, $12 \pm 2 \mathrm{~mm} \mathrm{~s}^{-1}$, deduced from the observed rise of the inversion with latitude between $0^{\circ}$ and $4^{\circ} \mathrm{N}$.
\end{abstract}

\section{Introduction}

The southeasterly winds that prevail over the eastern equatorial Pacific Ocean drive coastal and equatorial upwelling of cold water. In boreal summer and autumn, the water in the southern and equatorial tropical Pacific is cold and the intertropical convergence zone (ITCZ) is located around $10^{\circ} \mathrm{N}$, over the eastern Pacific warm pool. The East Pacific Investigation of Climate (EPIC) 2001 experiment (Raymond et al. 2004) investigated the processes responsible for atmospheric and oceanic coupling in the east Pacific. Among these processes are the evolution of the northward cross-equatorial atmo-

Corresponding author address: Dr. Simon P. de Szoeke, International Pacific Research Center, School of Ocean and Earth Science and Technology, University of Hawaii at Manoa, POST 413, 2525 Correa Road, Honolulu, HI 96822.

E-mail: deszoeke@hawaii.edu spheric boundary layer (ABL) flow upstream of the ITCZ. The ABL is stratocumulus-topped south of the equator, with some clearing as it crosses the equatorial cold tongue. Stratocumulus clouds become more pervasive as the air passes over the warmer SST to the north, until shallow convection breaks up the ABL clouds around $4^{\circ} \mathrm{N}$ (Klein and Hartmann 1993; Deser et al. 1993).

Before EPIC, there were few detailed observations of the cross-equatorial $\mathrm{ABL}$ evolution in this remote region except for near-surface meteorological measurements from Tropical Atmosphere Ocean (TAO) buoys at $95^{\circ}$ and $110^{\circ} \mathrm{W}$. Bond (1992) and Zeng et al. (2004) analyzed the vertical structure of the ABL measured with occasional soundings taken from research ships. Dropwinsondes over the eastern Pacific from the First Global Atmospheric Research Program Global Experiment (FGGE) during 1979 were analyzed by Yin and Albrecht (2000). 
As a part of EPIC 2001, eight aircraft flights along $95^{\circ} \mathrm{W}$ measured the $\mathrm{ABL}$ in situ and with dropwinsondes, providing instantaneous snapshots of the meridional-vertical structure of the $\mathrm{ABL}$ from the equator to the ITCZ and simultaneous measurements of turbulent surface fluxes. Here we study the mean and some statistical aspects of the flight-to-flight variability of the observations made on the eight flights, focusing on the $\mathrm{ABL}$ in the region from $1^{\circ} \mathrm{S}$ to $5^{\circ} \mathrm{N}$ where convection begins to penetrate the ABL inversion. We focus primarily on the downwind thermodynamic evolution of the $\mathrm{ABL}$ as air flows from south to north. A discussion of the processes controlling the ABL mean winds (but not their mean shear with height) is provided by McGauley et al. (2004).

A sharp front in the SST separates the equatorial cold tongue from the warm water to the north. Across the front there is remarkably sharp surface wind divergence (Chelton et al. 2001). We compare the mean ABL structure south and north of the front to test whether the wind increase north of the front is due to enhanced vertical mixing over the warmer SST there, as proposed by Wallace et al. (1989).

In the cold-advection boundary layer north of the SST front, we use the EPIC $95^{\circ} \mathrm{W}$ flight observations to relate the northward evolution of the mean ABL structure to the vertical structure of turbulent mixing and cloudiness within the ABL. We compute mass, heat, and moisture budgets and use them to obtain several independent estimates of the entrainment rate. These observations provide data that enable critical comparison of numerical simulations, including large eddy simulation (LES; de Szoeke and Bretherton; 2004) and regional models (N. Thum et al. 2003, personal communication; Wang et al. 2004).

Section 2 describes the data collected along $95^{\circ} \mathrm{W}$ from the intensive observation period of EPIC 2001 as well as our methods for processing the data. Section 3 describes the mean ABL structure. Section 4 presents heat and moisture budgets for the ABL between $1^{\circ}$ and $3^{\circ} \mathrm{N}$, and section 5 summarizes our findings.

\section{Data sources and methods}

Observations from aircraft, ship, satellite, and moored instrument platforms were synthesized to provide a comprehensive view of conditions observed in the cold season of 2001 along $95^{\circ} \mathrm{W}$. In September and October of 2001, as part of the EPIC 2001 field project (Raymond et al. 2004), the NCAR C-130 research aircraft flew eight missions from Huatulco, Mexico, to the equator and back along the $95^{\circ} \mathrm{W}$ meridian. The aircraft flew south in the porpoising pattern shown in Fig. 1. This pattern included level legs at 30- and 1600-m altitude, interspersed with ascent and descent profiles. The 30-m legs typically spanned $30 \mathrm{~km}$ in latitude, while the $1600-\mathrm{m}$ legs spanned $40 \mathrm{~km}$. The locations and lengths of the legs are indicated by the vertical line segments in Fig. 2. We estimate vertical fluxes from covariances of vertical velocity with velocity, temperature, and humidity data sampled at a rate of $25 \mathrm{~Hz}$. While ferrying back north, the aircraft dropped dropwinsondes from an altitude of $5.5 \mathrm{~km}$ at intervals of $1^{\circ}$ of latitude.

Also as a part of EPIC 2001, the National Oceanic and Atmospheric Administration (NOAA) Research Vessel Ronald H. Brown (hereafter the Brown) steamed southward along $95^{\circ} \mathrm{W}$, collecting high-rate measurements of the near-surface atmosphere, clouds, and the upper ocean. The Brown's progress along $95^{\circ} \mathrm{W}$ was irregular; it was on station at $10^{\circ} \mathrm{N}$ in the vicinity of the ITCZ for the early portion of the aircraft program and

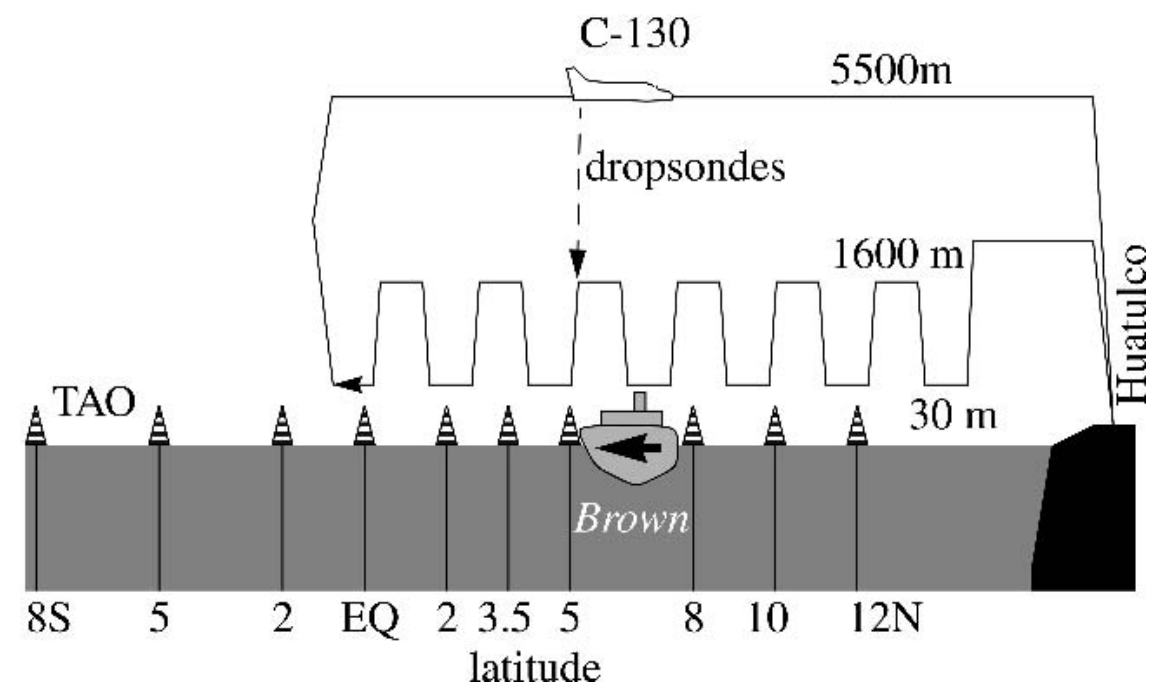

FIG. 1. Observation platforms for EPIC $95^{\circ} \mathrm{W}$, including the NCAR C-130 aircraft, dropwinsondes, the TAO mooring array, and the NOAA Research Vessel Ronald H. Brown. 


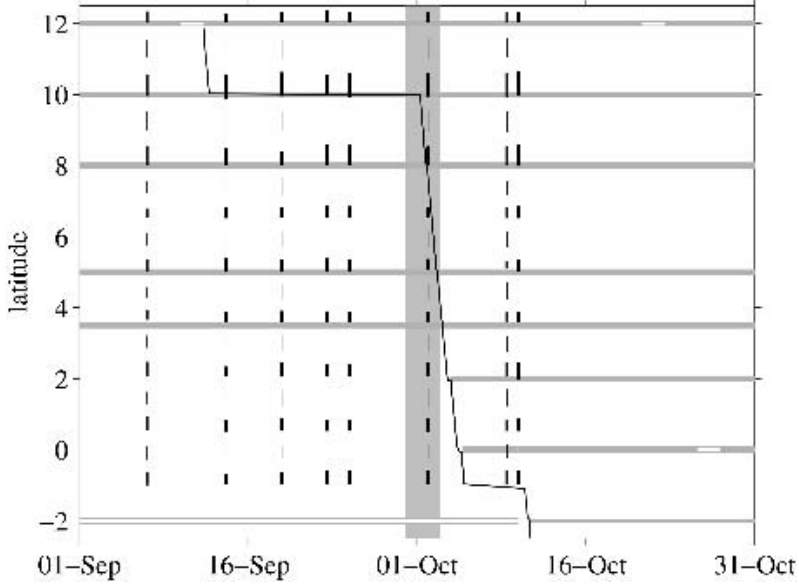

FIG. 2. The temporal and spatial coverage of the aircraft, TAO buoy, and ship surface measurements during EPIC 2001. C-130 flights are shown by vertical lines. Thick vertical lines indicate the location and extent of the 30-m legs; thin lines indicate the 1600-m legs. The transect of the Brown is marked with a solid black line. The TAO buoy SST and wind speed data availability for each latitude is indicated by the horizontal gray lines. Double horizontal gray lines show when the SST was available, thin gray lines show when the wind speed was available, and thick filled gray lines show when both the SST and wind speed were available. The three days of TMI data averaged together for the SST in Fig. 3 are indicated by the vertical gray band.

stopped to service the TAO moorings on its way to the equator.

The TAO buoys provide long time series of data from observations of the surface atmosphere, the SST, and the upper ocean (Cronin et al. 2002). Unfortunately, the array suffered losses due in large part to fishing-related vandalism that resulted in some data gaps during EPIC 2001. The temporal and spatial distribution of aircraft, buoy, and ship surface measurements along $95^{\circ} \mathrm{W}$ is shown in Fig. 2. The Tropical Rainfall Measuring Mission (TRMM) Microwave Imager (TMI) provides radiometric SST observations with finer spatial resolution than the TAO buoy array, though not as fine as the single transect of ship observations. Unless otherwise noted, all data were obtained from the Joint Office for Science Support (JOSS) EPIC data archive Web site (http://www.joss.ucar.edu/epic/ dm/data_access_frame.html). Documentation about these datasets can be found there.

\section{a. Surface observations and flux calculations}

\section{1) C-130 observations}

Three-dimensional velocity, pressure, temperature, and humidity were recorded in situ at $25 \mathrm{~Hz}$ for the entirety of each C-130 flight. The velocity was measured by differential pressure transducers and adjusted for the motion of the aircraft using a global positioning system (GPS) and an inertial correction. Water vapor mixing ratio was measured by a Lyman-alpha optical sensor insensitive to in-cloud wetting biases, and the liquid water content was measured by a Gerber liquid water sensor. Broadband radiative fluxes were measured at $1 \mathrm{~Hz}$ by shortwave and longwave radiometers on the top and bottom of the C-130 aircraft. These data were corrected for the pitch and roll angles of the aircraft. Near-surface air pressure and temperature were derived from measurements during the 30-m legs and adjusted down to the equivalent sea surface assuming a hydrostatic, isentropic layer between the flight altitude (derived by radar altimeter) and the surface.

We compared the SST inferred from a downwardlooking PRT-5 water vapor window channel radiometer on the C-130 during the $30-\mathrm{m}$ legs and SST measured by the Brown's floating thermometer at $5-\mathrm{cm}$ depth and the TAO buoys at 1-m depth while the C-130 was overhead. The TAO and the Brown SST were consistent. The C-130 radiometer measured a sea surface skin temperature. The skin temperature is cooled by evaporation and heated by solar radiation, relative to the bulk SST. Skin temperature estimates from the Coupled Ocean-Atmosphere Response Experiment (COARE) v.3.0 algorithm take into account cooling of the skin by evaporation and warming of the skin by solar radiation. Typical skin adjustments were $-0.2^{\circ} \mathrm{C}$, though they were less on average in the ITCZ where there were intervals of calm sunny weather. The C-130 radiometric skin temperature was compared to the skin temperature derived from the TAO data by the COARE algorithm and found to be biased $0.83^{\circ} \mathrm{C}$ warmer than the TAO skin temperature. Assuming the offset could be attributed to a constant bias from the calibration of the aircraft infrared radiometer, we subtracted $0.83^{\circ} \mathrm{C}$ from the aircraft SST. Figure 3 shows the high degree of agreement between the four platforms after the aircraft SST bias has been removed.

Vertical turbulent fluxes of zonal velocity $u$, meridional velocity $v$, temperature $T$, and moisture $q_{v}$ were estimated by the eddy correlation method from the 25$\mathrm{Hz}$ data collected on the $30-\mathrm{m}$ legs,

$$
\begin{aligned}
\tau_{x} & =\rho \overline{u^{\prime} w^{\prime}}, \\
\tau_{y} & =\rho \overline{v^{\prime} w^{\prime}}, \\
F_{\text {sfc }}^{T} & =\rho C_{P} \overline{T^{\prime} w^{\prime}}, \\
F_{\text {sfc }}^{q} & =\rho L \overline{q_{v}^{\prime} w^{\prime}},
\end{aligned}
$$

where $\tau_{x}$ and $\tau_{y}$ are the zonal and meridional wind stresses in $\mathrm{Pa}, F_{\mathrm{sfc}}^{T}$ and $F_{\mathrm{sfc}}^{q}$ are the sensible and latent heat fluxes in $\mathrm{W} \mathrm{m}{ }^{-2}, \rho$ is the air density, $C_{P}$ is the specific heat at constant pressure of dry air, and $L$ is the latent heat of vaporization of water. The overbar represents an average over $40 \mathrm{~s}$ (roughly $4 \mathrm{~km}$ ), corresponding to $N=10^{3} 25-\mathrm{Hz}$ samples. The perturbations, denoted by primes, have had the mean and the trend over the averaging window removed. The 40-s window corresponds to a horizontal aircraft displacement of 


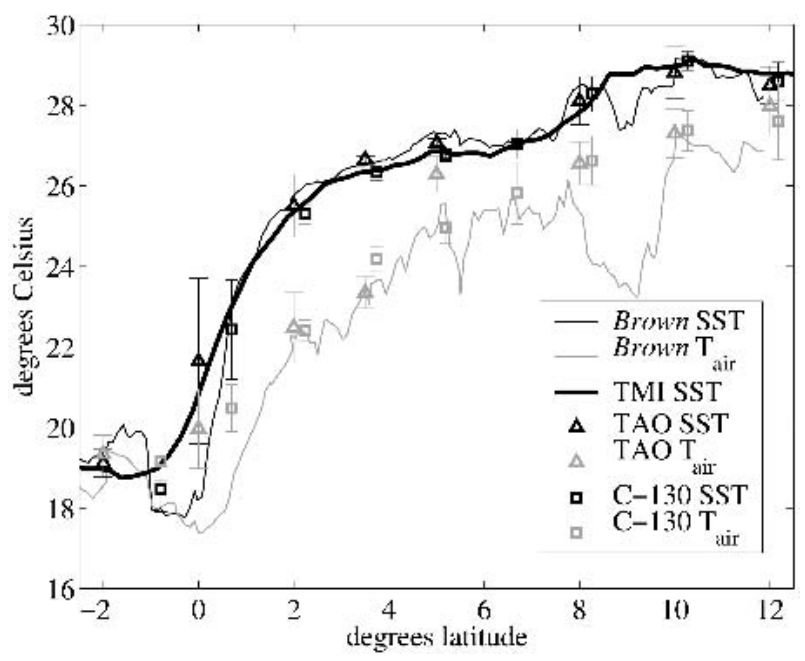

FIG. 3. SST (black) and surface air temperature (gray) for SepOct 2001 were measured by the Brown (thin lines), the TAO moorings (triangles), and the C-130 aircraft (squares). The SST was also measured by the TMI satellite (thick line). Daily TAO observations were averaged over the 2 months. TMI observations were averaged over 30 Sep- 2 Oct. The C-130 data are the average of all eight $95^{\circ} \mathrm{W}$ flights. The vertical bars indicate the standard deviation of the daily TAO data and standard deviation among the eight C-130 flights. The Brown data are from a single transect of the ship.

roughly 10 times the average mixed layer depth and 3-4 times the typical ABL depth. Means and variances computed on such a time scale empirically have been found to retain the effects of the flux-transporting eddies but exclude the effects of mesoscale variability and drift in the vertical velocity estimates (Lenschow et al. 1994). Power spectra of vertical velocity (not shown) suggest this window length samples almost all of the vertical velocity variance sampled in the full time series of the $30-\mathrm{m}$ legs. Since the estimates of the mean and trend each remove a degree of freedom, the overbar is given by

$$
\overline{()}=\sum_{1}^{N}() /(N-2)
$$

The surface fluxes and stresses for a given 30-m leg are taken as the mean of all the 4-km windows in that leg. Fluxes were also estimated from aircraft data using the COARE v.3.0a bulk flux algorithm (Fairall et al. 2003). The skin temperature correction for radiative heating and evaporative cooling of the water surface in this algorithm was not used since the SST radiometrically measured by the $\mathrm{C}-130$ is already a direct measurement of the skin temperature.

\section{2) TAO BUOY MEASUREMENTS}

TAO moorings at $8^{\circ} \mathrm{S}, 5^{\circ} \mathrm{S}, 2^{\circ} \mathrm{S}, 0^{\circ}, 2^{\circ} \mathrm{N}, 3.5^{\circ} \mathrm{N}, 5^{\circ} \mathrm{N}$, $8^{\circ} \mathrm{N}, 10^{\circ} \mathrm{N}$, and $12^{\circ} \mathrm{N}, 95^{\circ} \mathrm{W}$ provide long, highresolution ( $1 \mathrm{~h}$ or better) observations of surface wind, pressure, temperature, humidity, shortwave and long- wave radiative flux, SST, and surface currents. TAO data from September and October 2001 were obtained from the TAO Web site (http://www.pmel.noaa.gov/ tao/data_deliv/). The TAO moorings at the equator and $2^{\circ} \mathrm{N}$ were inoperable until they were repaired early in October. The TAO buoy at $2^{\circ} \mathrm{S}$ did not record SST after 10 October 2001. Averages presented here are performed over all the available data (Fig. 2).

Bulk wind stress and latent and sensible heat fluxes were computed using the COARE v.3.0a bulk flux algorithm applied to hourly averaged TAO data. In particular, the algorithm's cool skin parameterization and simplified 1D mixed layer model were used to extrapolate the bulk SST measurements to the sea surface interface. Because at times winds were weak, currents were not ignored in the TAO bulk flux calculations. The available observed TAO surface currents, or climatological surface currents (Johnson et al. 2002), were used to compute the winds relative to the air-sea interface in the flux and stress calculations. Fluxes were averaged daily before computing their standard deviation.

Table 1 shows the heights at which the C-130 aircraft, the Brown, and the TAO buoys observed surface meteorological variables. The winds presented in this paper have been adjusted to a reference height of $10 \mathrm{~m}$ using the COARE bulk flux algorithm, which typically yields a roughness length of $8 \times 10^{-5} \mathrm{~m}$. Surface air temperatures have been adjusted to sea level using the dry adiabatic lapse rate.

\section{3) SAtellite observations}

SST derived from the TMI instrument on the TRMM satellite was obtained from Remote Sensing Systems (available online at http://www.ssmi.com/tmi/tmi_browse. $\mathrm{html}$ ), with a geographic resolution of $0.25^{\circ} \times 0.25^{\circ}$. The TMI swaths are guaranteed to sample all locations only every 3 days (six swaths), so the TMI daily gridded data are the average of all available samples within a centered 3-day window. The TMI cannot retrieve SST in locations experiencing heavy rainfall.

Images from Geostationary Operational Environmental Satellite-8 (GOES-8) were taken from the JOSS EPIC data archive Web site.

TABLE 1. Heights $(\mathrm{m})$ for each platform and observation type.

\begin{tabular}{cccc}
\hline \hline & C-130 & Brown & TAO \\
\hline$u, v^{\mathrm{a}}$ & $30^{\mathrm{b}}$ & 18.5 & 4 \\
$T_{\text {air }}^{\mathrm{c}}$ & 30 & 15.5 & 3 \\
$q_{\text {air }}$ & 30 & 15.5 & 3 \\
SST & $0^{\mathrm{d}}$ & -0.05 & -1 \\
\hline
\end{tabular}

${ }^{\text {a }}$ Winds are adjusted to a height of $10 \mathrm{~m}$ with the COARE algorithm.

b $30 \mathrm{~m}$ is the nominal flight altitude for the " $30 \mathrm{~m}$ " legs.

${ }^{\mathrm{c}}$ Surface air temperature is adiabatically adjusted to the level of the surface.

d The C-130 observes a radiometric skin temperature. 


\section{b. Cross sections from in situ aircraft and dropwinsonde observations}

The C-130 aircraft made profiles of the atmosphere between 30- and 1600-m altitude during its ascending and descending legs (see Fig. 1). Observations from the aircraft profiles were binned by GPS altitude and averaged onto a $20-\mathrm{m}$ vertical grid. Since the flight pattern was almost the same for all EPIC $95^{\circ} \mathrm{W}$ flights, the mean latitudes of the profiles were nearly collocated among flights. To compare the data among all the $95^{\circ} \mathrm{W}$ flights, we computed the mean latitude of the collocated profiles and assigned the profiles to these nominal latitudes. The result is a 3D array for each variable, indexed to latitude, height, and flight number.

The vertical velocity variance $\overline{w^{\prime 2}}$ profile was used as a measure of turbulence. It was computed from the $25-\mathrm{Hz}$ vertical velocity after windowing and detrending 40-s intervals in the same way as for the $30-\mathrm{m}$ legs. The vertical velocity variance was preferred as a measure of turbulence over the turbulent kinetic energy, $\overline{u^{\prime 2}}+\overline{v^{\prime 2}}$ $+\overline{w^{\prime 2}}$ because the horizontal velocity variance includes sizable effects of mesoscale wind variability and not just the turbulence per se. The vertical velocity variance was computed on the 20 -m grid, though the 40 -s averaging window corresponded to aircraft vertical displacement of $\delta z \approx 160 \mathrm{~m}$ so each vertical velocity variance estimate was not statistically independent of its nearest eight neighbors. The vertical velocity variance below the lowest estimate was interpolated between the lowest estimate and the surface where the vertical velocity must be zero.

While the C-130 flew northward on the return ferry, it released dropwinsondes from an altitude of $5.5 \mathrm{~km}$ at each degree of latitude between the equator and $12^{\circ} \mathrm{N}$. The dropwinsondes measured pressure, temperature, and humidity and were tracked as they fell to obtain horizontal velocities. Each dropwinsonde profile was averaged to a 5-hPa vertical grid. A mean latitudealtitude cross section of the atmosphere at $95^{\circ} \mathrm{W}$ was obtained by averaging together for all flights the dropwinsonde profiles at the same latitudes.

\section{c. Optical cloud observations}

Radiative observations from the aircraft were used to quantify the cloudiness in the ABL. During the return ferry at $5500 \mathrm{~m}$ between $0.5^{\circ}$ and $12^{\circ} \mathrm{N}$, the C-130 aerosol backscatter lidar was pointed toward the surface. A range-dependent backscatter threshold was used to determine the presence and altitude of cloud tops. We computed ABL cloud fraction as the ratio of the lidar cloud tops between 50 and $1500 \mathrm{~m}$ to the "tops" below $50 \mathrm{~m}$. Cloud fraction was calculated in this manner for each $0.2^{\circ}$ latitude bin between $0.5^{\circ}$ and $12^{\circ} \mathrm{N}$. This method did not count scenes masked by middle clouds (cloud tops above $1500 \mathrm{~m}$ ), which were generally above the ABL top. Backscatter from middle clouds was practically less than $10 \%$ except between $5^{\circ}$ and $9^{\circ} \mathrm{N}$, where cumulus congestus occupied $30 \%$ of the scenes. Low cloud fraction was not calculated for $0.2^{\circ}$ bins that had fewer than 50 lidar backscatters below $1500 \mathrm{~m}$, equivalent to excluding the low cloud fraction where the middle clouds masked more than $2 / 3$ of the scene.

Albedo at $1600 \mathrm{~m}$,

$$
\alpha_{1600 \mathrm{~m}}=F_{\text {solar }}^{\uparrow} / F_{\text {solar }}^{\downarrow},
$$

was calculated from the solar radiometers on the top and bottom of the C-130 during each $1600-\mathrm{m} \mathrm{leg}$. Here $F_{\text {solar }}^{\uparrow}$ and $F_{\text {solar }}^{\downarrow}$ are the attitude-corrected leg mean upwelling and downwelling solar radiation measured at the bottom and top of the C-130 fuselage, respectively.

\section{The mean state along $95^{\circ} \mathrm{W}$}

\section{a. Surface observations}

Some of the largest SST gradients in the open tropical ocean are observed between the equatorial cold tongue and the eastern Pacific warm pool (Raymond et al. 2004). The ABL here responds primarily to the heating it experiences from the ocean surface, which results from its being advected over increasingly warmer water. Figure 3 shows the mean SST observations during September and October 2001 from the Brown, the TMI, the TAO buoys, and the C-130 flights (black lines and symbols). TAO observations are averaged over the entire 2-month period and C-130 observations are averaged over the $8 \mathrm{EPIC} 95^{\circ} \mathrm{W}$ flights. Vertical bars on the temperatures denote the standard deviations of intersample variability of the daily TAO data in September-October 2001, or the standard deviations of the C-130 data sampled among the eight flights. The single set of Brown data and the 3-day average of TMI swath data from 30 September to 2 October provide realizations of the sharp SST gradient that can be observed. Some differences between the TAO buoy data and the C-130 data can be explained by a seasonal trend and different sampling by the two platforms. The equatorial TAO buoy only started recording SST in October, while the C-130 flights were in September and early October.

The SST is about $19^{\circ} \mathrm{C}$ just south of the equator and warmer than $24^{\circ} \mathrm{C}$ north of $1^{\circ} \mathrm{N}$ with a SST front around the equator. The SST front is known to meander meridionally on weekly time scales due to tropical instability waves (Legeckis 1977; Contreras 2002). This meandering smears out the SST front in the 2-month averages, but the instantaneous ship observations resolve the front's fine spatial scale. From $1^{\circ} \mathrm{N}$ to the equator the ship measured a drop in SST from $23.8^{\circ}$ to $18.2^{\circ} \mathrm{C}$.

Figure 3 also shows near-surface air temperatures adjusted to 10-m height (in gray) for September-October 2001 from the Brown, TAO, and C-130. As the air moves northward, there is a transition from a warmadvection ABL just south of the equator, where surface air temperature is slightly warmer than the SST, to a 
cold-advection ABL, where the surface air temperature is considerably cooler than the SST. On this cruise, the air-sea temperature differences peaked at about $-4^{\circ} \mathrm{C}$ around $1^{\circ} \mathrm{N}$. Except at $5^{\circ} \mathrm{N}$ the TAO air temperature agreed with the adiabatically adjusted C-130 air temperature.

Surface heat fluxes respond to this large air-sea temperature difference north of the SST front. Mean sensible and latent heat fluxes are shown as a function of latitude in Fig. 4. Bulk heat fluxes averaged over the north-south 30-m altitude legs on all flights are indicated by squares for the C-130 aircraft. Triangles indicate averages of the available TAO buoy data for September-October 2001. Heat fluxes calculated by the eddy correlation method from the $25-\mathrm{Hz}$ C-130 observations are indicated by circles. Vertical bars indicate the standard deviation of the daily averaged TAO fluxes during September-October 2001, or the standard deviation of the fluxes over the eight C-130 flights. The standard deviations are estimates of the day-to-day sampling variability and not estimates of the error of the mean per se. Although the TAO and C-130 sam-

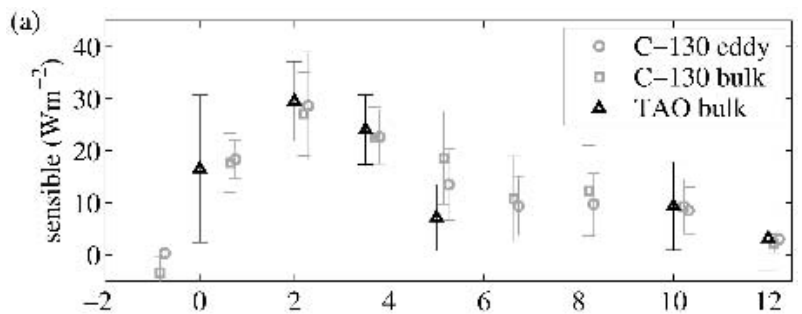

(b)
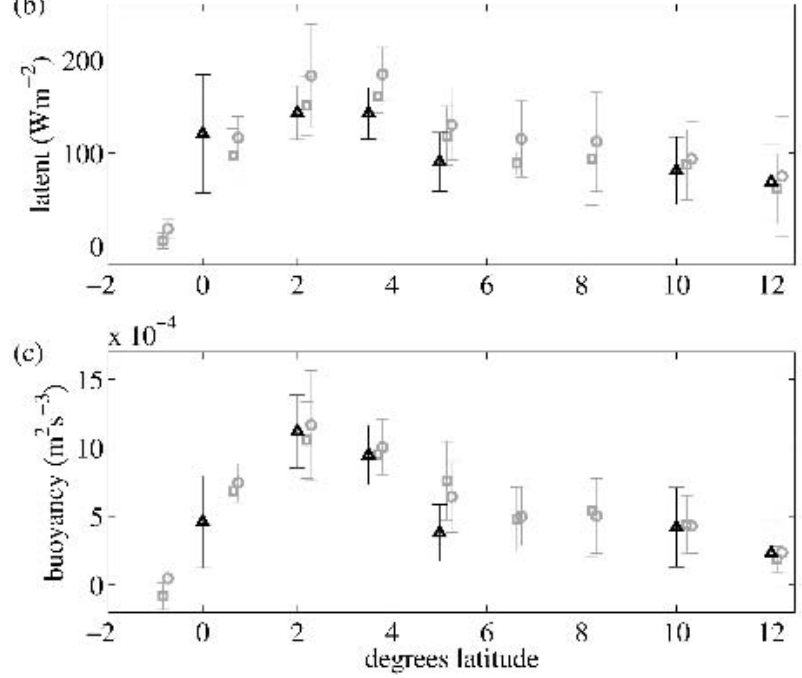

FIG. 4. Surface (a) sensible and (b) latent heat fluxes observed during EPIC $95^{\circ} \mathrm{W}$. Average bulk fluxes over the observations taken in Sep-Oct 2001 are computed for the TAO buoys (triangles) and the C-130 (squares). Eddy correlation fluxes from the C-130 are indicated by circles. The bulk and eddy correlation fluxes from the C-130 are shifted apart slightly in the plot for clarity. The vertical bars show the standard deviations about the mean of the data. pling periods are different, the mean biases seen in Fig. 4 are comparable to those seen if only the TAO data from the hour of the C-130 overpasses are averaged for the comparison.

The eddy correlation latent heat fluxes agree moderately well with the latent heat flux calculated from the bulk method. The C-130 eddy correlation sensible heat flux is very close to the C-130 and TAO bulk sensible heat flux except at $5^{\circ} \mathrm{N}$, where Fig. 3 suggests that there is nearly a $2-\mathrm{K}$ warm bias in the TAO-measured air temperature. The C-130 bulk latent heat flux is $0-30 \mathrm{~W}$ $\mathrm{m}^{-2}$ lower than the $\mathrm{C}-130$ eddy correlation latent heat flux. Between $2^{\circ}$ and $5^{\circ} \mathrm{N}$ the TAO bulk latent heat flux is even lower (by $20 \mathrm{~W} \mathrm{~m}^{-2}$ ). At $5^{\circ} \mathrm{N}$ this probably reflects the TAO temperature bias, combined with a reasonable TAO relative humidity measurement. There are comparable potential observational biases in each of the three latent heat flux estimates, so we regard all three estimates as similarly reliable.

South of the equator the sensible heat flux is near zero, and the latent heat flux is small $\left(10 \mathrm{~W} \mathrm{~m}^{-2}\right)$. The surface heat fluxes are at a maximum around $2^{\circ} \mathrm{N}$, where the sensible heat flux reaches $30 \mathrm{~W} \mathrm{~m}^{-2}$ and the latent heat flux exceeds $160 \mathrm{~W} \mathrm{~m}^{-2}$. The fluxes decrease gradually north of $2^{\circ} \mathrm{N}$ as the air-sea temperature difference becomes smaller in magnitude. In the ITCZ region the sensible heat flux is about $10 \mathrm{~W} \mathrm{~m}^{-2}$ and the latent heat flux is about $100 \mathrm{~W} \mathrm{~m}^{-2}$.

The convective overturning that takes place due to the surface heat fluxes is induced dynamically by buoyancy. The surface buoyancy flux,

$$
B=\frac{g}{\bar{T}_{v}} \overline{w^{\prime} T_{v}^{\prime}}=g\left[\frac{\overline{w^{\prime} T^{\prime}}}{\bar{T}}+\frac{0.61 \overline{w^{\prime} q_{v}^{\prime}}}{1+0.61 \overline{q_{v}}}\right],
$$

is shown in Fig. 4c. Substituting (3) and (4), the surface buoyancy flux can be obtained from the latent and sensible heat fluxes in Figs. $4 \mathrm{a}$ and $4 \mathrm{~b}$. The surface buoyancy flux is at a minimum at the equator and at a maximum of $1.2 \times 10^{-3} \mathrm{~m}^{2} \mathrm{~s}^{-3}$ at $2^{\circ} \mathrm{N}$.

The surface wind is linked to the strong SST gradient and vertical eddy mixing, which is related to the surface buoyancy flux. As in the climatology, 10-m surface wind observations for September-October 2001 (Fig. 5) show a wind minimum over the cold tongue. The mean and the standard deviation of the C-130 and the TAO winds are shown, as for the temperatures in Fig. 3. Meridional winds increased from $5 \mathrm{~m} \mathrm{~s}^{-1}$ at $1^{\circ} \mathrm{S}$ to $7 \mathrm{~m} \mathrm{~s}^{-1}$ at $2^{\circ} \mathrm{N}$. The zonal wind was relatively weak $\left(-2 \mathrm{~m} \mathrm{~s}^{-1}\right)$ within $2^{\circ}$ of the equator. Zonal winds tended to be more westerly to the north in the vicinity of the ITCZ (around $8^{\circ} \mathrm{N}$ ). Most of the convergence of the meridional wind occurred between $5^{\circ}$ and $10^{\circ} \mathrm{N}$.

Surface stresses are shown in Fig. 6. The components of the surface stress were large where the winds were strong, between $5^{\circ}$ and $9^{\circ} \mathrm{N}$ for the zonal wind and between $1^{\circ}$ and $5^{\circ} \mathrm{N}$ for the meridional wind. These regions coincided with negative air-sea temperature 
(a)

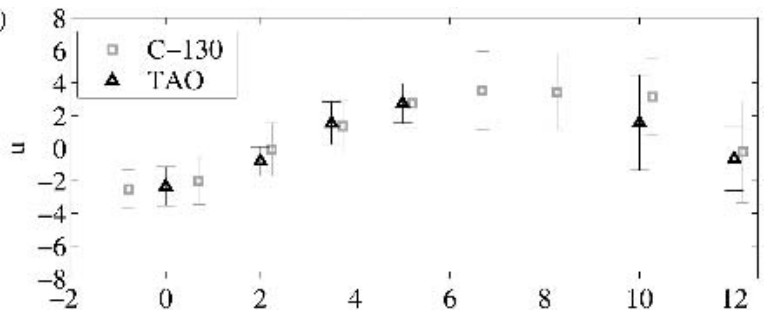

(b)

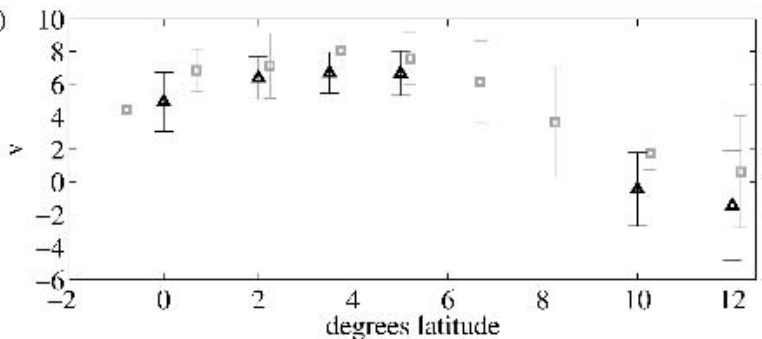

FIG. 5. The 10-m (a) zonal and (b) meridional wind measured by the same platforms as in Fig. 3. Winds have been adjusted from the measurement height to $10 \mathrm{~m}$ with the COARE algorithm. Vertical bars show the standard deviations about the mean of the data.

differences. South of the equator where the air-sea temperature difference was positive, the high surface stability corresponds to reduced surface wind speed and reduced wind stress. North of $2^{\circ} \mathrm{N}$, the zonal eddy correlation stresses seem to be offset by $0.01 \mathrm{~Pa}$ from the bulk stresses. The meridional stresses computed by the eddy correlation method (not shown) are only about a third of the magnitude of the bulk meridional stresses. After considerable study of this issue, it was concluded that there were significant measurement errors in the high-frequency wind along the direction of flight, which affects the meridional stresses computed on north-
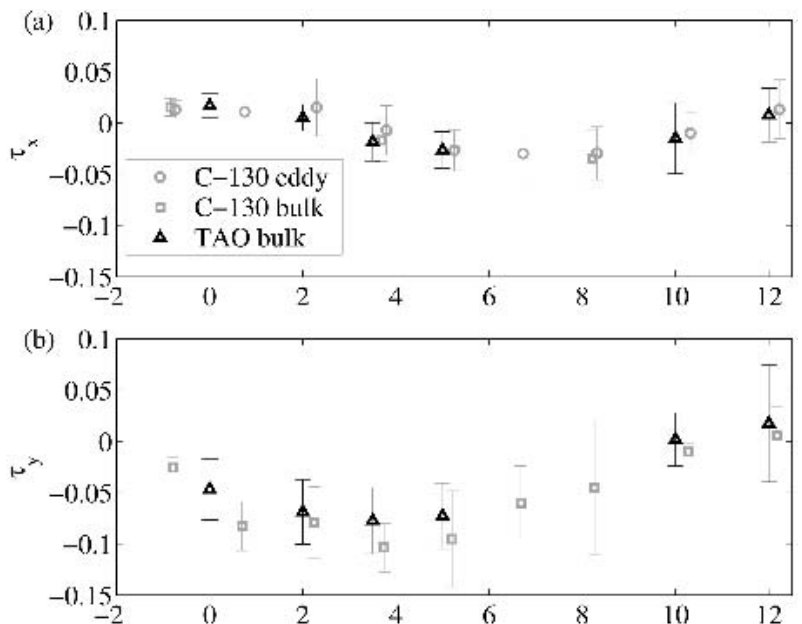

FIG. 6. (a) Zonal and (b) meridional surface stresses on the atmosphere. The observations, platforms, and plotting symbols are as in Fig. 4. south flight legs. In an independent analysis, S. Esbensen (2003, personal communication) reached similar conclusions. In response, NCAR has released a revised dataset that partially corrects these problems, but this dataset was not available for all flights in time for this analysis.

\section{b. $95^{\circ} \mathrm{W}$ mean vertical structure}

Dropwinsondes released from the C-130 measured atmospheric variables at $1^{\circ}$ intervals between the equator and $12^{\circ} \mathrm{N}$ along $95^{\circ} \mathrm{W}$. Latitude-altitude cross sections of potential temperature, relative humidity, zonal wind, and meridional wind averaged over all eight flights are presented in Fig. 7. The dropwinsonde data were averaged to 5 -hPa intervals in the vertical, and the velocity data were smoothed with a running $1-2-1$ weighted filter. The boundary layer inversion (the
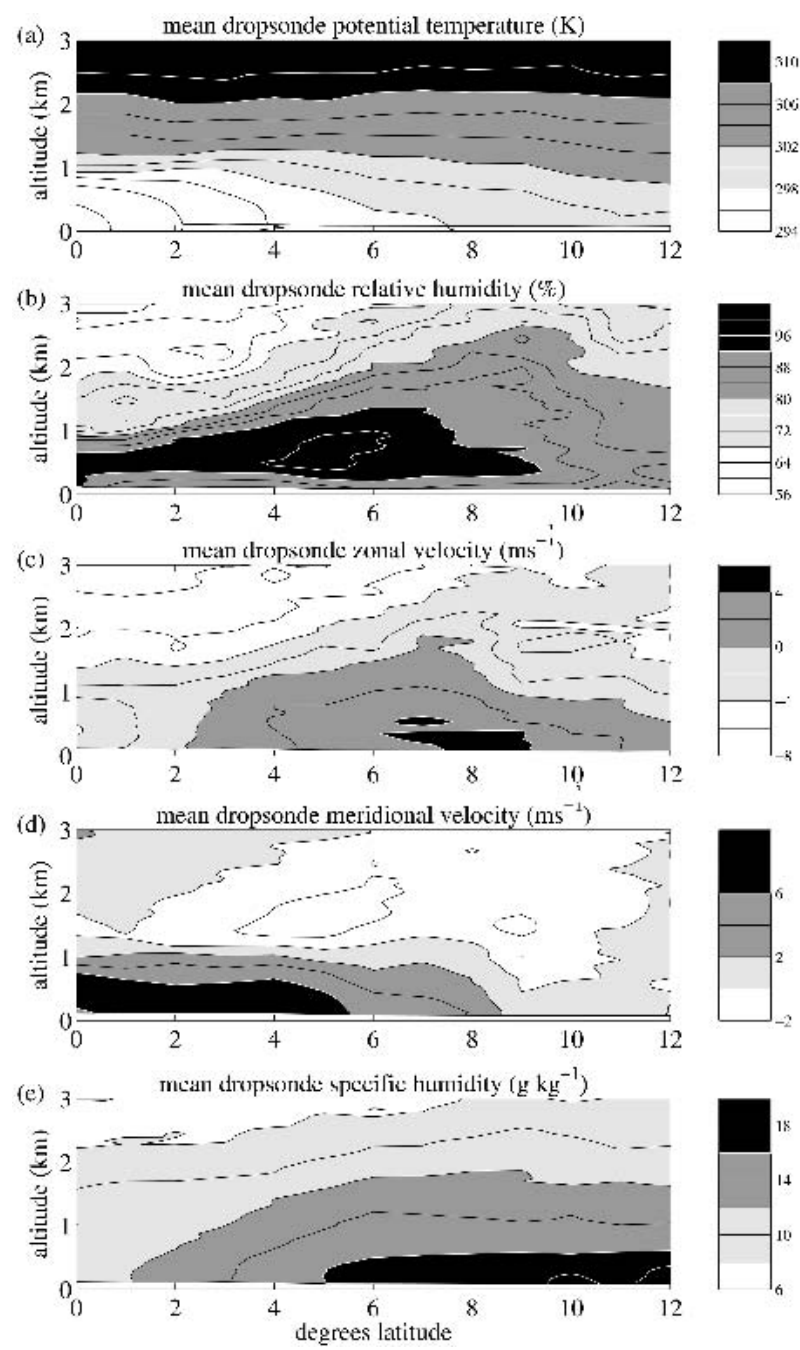

FIG. 7. Mean latitude-altitude dropwinsonde cross sections showing the (a) potential temperature, (b) relative humidity, (c) zonal velocity, (d) meridional velocity, and (e) specific humidity. 
stable layer near $1000 \mathrm{~m}$ in Fig. 7a) defines the top of the ABL. The inversion rose and weakened in stability from the equator to $4^{\circ} \mathrm{N}$. The height of the inversion base was discerned by eye from the $\mathrm{C}-130$ profiles. Inversions south of $3.3^{\circ} \mathrm{N}$ were observed on all flights. At $4.2^{\circ} \mathrm{N}$ five of the flights had clearly defined inversions, and at $4.7^{\circ} \mathrm{N}$ only flight 11 had a clearly defined inversion. The height of the inversion is discussed further at the end of this section.

The mean relative humidity cross section in Fig. $7 \mathrm{~b}$ shows a wedge of high-humidity air widening between $1^{\circ}$ and $10^{\circ} \mathrm{N}$. This widening wedge of relative humidity is the combined signal of the rising boundary layer top, and the increased frequency of shallow cumulus convection penetrating the inversion and moistening the free troposphere. The relative humidity marks the boundary layer more clearly than the specific humidity because the free troposphere was often as moist as the ABL. For reference, the specific humidity is shown in Fig. 7e.

Easterlies (Fig. 7c) of $-4 \mathrm{~m} \mathrm{~s}^{-1}$ were observed in mid-boundary layer over the cold tongue. The crossequatorial southerlies (Fig. $7 \mathrm{~d}$ ) reached up to $8 \mathrm{~m} \mathrm{~s}^{-1}$ and were confined to the boundary layer. The dropwinsondes at the equator sampled the edge of the minimum in surface wind speed over the cold tongue. A weak return circulation in the mean was observed above the boundary layer at $1.2-2.8-\mathrm{km}$ height with average $1.25 \mathrm{~m} \mathrm{~s}^{-1}$ northerlies between $3^{\circ}$ and $8^{\circ} \mathrm{N}$.

The transition of the lower ABL from stable stratification over the cold tongue to unstable stratification over the warm water to the north is shown by C-130 aircraft profiles, which extend farther south than the dropwinsondes. Figure 8 shows eight-flight mean profiles of the potential temperature $\theta$ at $0.5^{\circ} \mathrm{S}$, in the middle of the cold tongue, and $1^{\circ} \mathrm{N}$, on the warm side of the SST front. To preserve the vertical structure, before averaging the vertical coordinate is normalized below the inversion to match the inversion base height in each profile to the mean inversion base height. Above the inversion base, the vertical coordinate is translated to match each inversion base height to the mean inversion base height. The thin lines show the interflight standard deviation of the potential temperature observed over the eight flights. Below the inversion, this is based on the normalized vertical coordinate. Above the inversion the standard deviation is calculated before translating the vertical coordinate because the lower freetropospheric temperature profile does not strongly depend on the inversion height. The standard deviation of the inversion base height among the eight flights is denoted by the length of the thin vertical lines centered at the inversion base height.

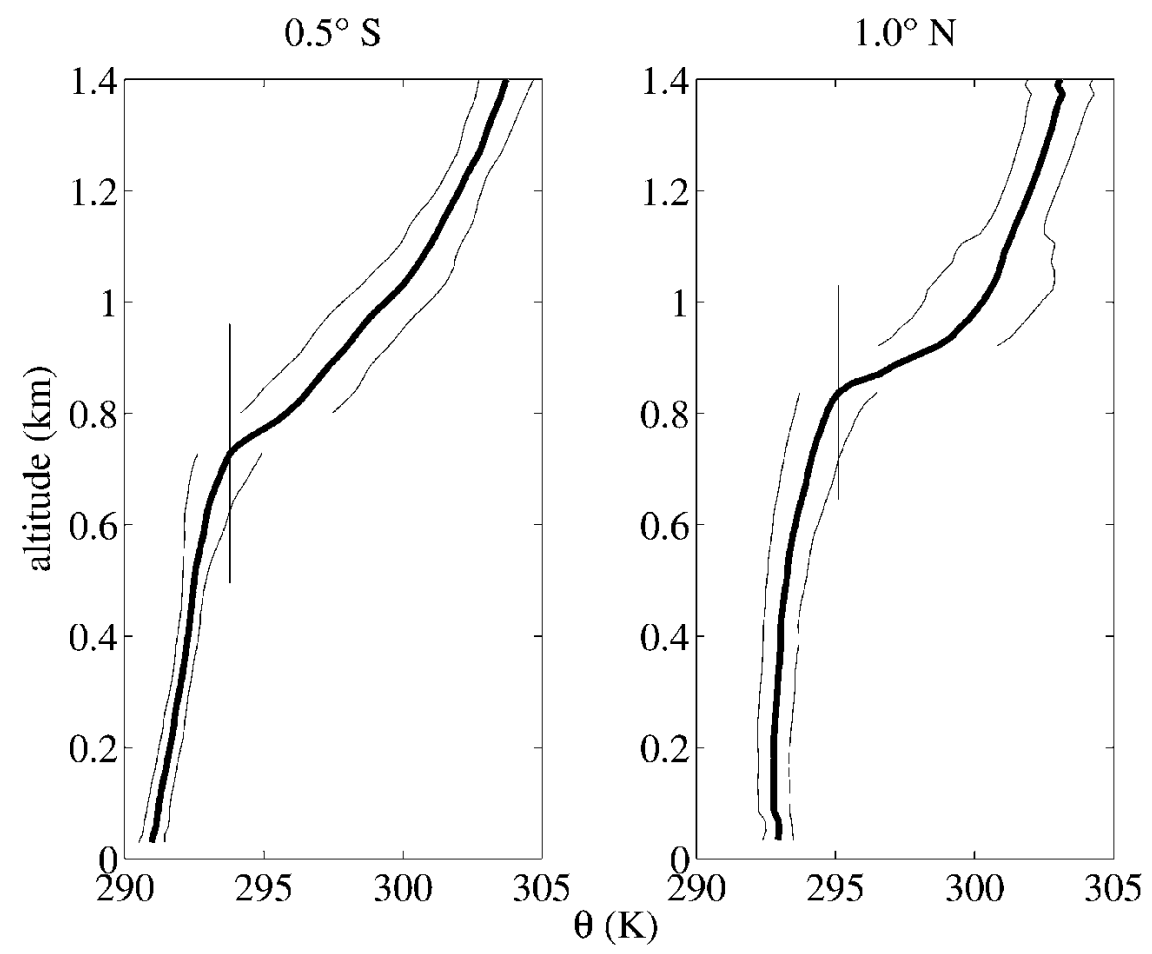

FIG. 8. Profiles of the mean potential temperature $\theta$ at $0.5^{\circ} \mathrm{S}$ and $1^{\circ} \mathrm{N}$ for the eight $95^{\circ} \mathrm{W}$ flights. To preserve the vertical structure in the mean, the vertical coordinate has been normalized below the inversion and translated above the inversion before averaging to match each inversion to the mean inversion height. The thin lines about the profiles show $1 \mathrm{std}$ dev about the observations. The thin vertical lines denote the std devs about the mean inversion height. 
At $0.5^{\circ} \mathrm{S}$ the mean inversion base was at $750 \mathrm{~m}$. The stable inversion layer extends above $1000 \mathrm{~m}$ in the free troposphere, which is characteristic of a boundary layer with weak entrainment. At $1^{\circ} \mathrm{N}$ a moist adiabatic layer can be recognized in the mean between $600-\mathrm{m}$ and 850-m height, which was typically occupied by stratocumulus clouds. The cloud layer was capped above with an inversion layer from 850 to $1000 \mathrm{~m}$. At $0.5^{\circ} \mathrm{S}$ the layer between the surface and $400 \mathrm{~m}$ had stable stratification, $\partial \bar{\theta} / \partial z=3 \mathrm{~K} \mathrm{~km}^{-1}$, while at $1.0^{\circ} \mathrm{N}$ this layer was well mixed.

Figure 9 shows the wind speed profiles corresponding to the potential temperature profiles in Fig. 8. At $0.5^{\circ} \mathrm{S}$, where the near-surface layer was stably stratified, the mean wind speed increased $4 \mathrm{~m} \mathrm{~s}^{-1}$ from the surface to a jet at $0.4-0.6 \mathrm{~km}$. At $1.0^{\circ} \mathrm{N}$ the jet was absent and the momentum was mixed from the surface to $0.6 \mathrm{~km}$. The observed structure is consistent with past observations and predicted by large-eddy simulations (de Szoeke and Bretherton 2004).

Figure 10 shows the mean profiles of vertical velocity variance and cloud liquid water content along $95^{\circ} \mathrm{W}$. The vertical coordinate is normalized before averaging so that the inversion height in each profile is equal to the mean inversion height. In Fig. 10, the vertical velocity variance below the height of the lowest estimate is interpolated between the lowest estimate and the surface, where the vertical velocity must be zero. The ver- tical velocity variance $\overline{w^{\prime 2}}$ is largest in the lowest $500 \mathrm{~m}$ of the ABL between the equator and $5^{\circ} \mathrm{N}$. Above 0.5 $\mathrm{km}$ patchy turbulence in cumulus and stratocumulus was observed over the warm SST where the surface buoyancy fluxes drive vigorous convection in a subcloud mixed layer. Farther north the subcloud mixedlayer convection diminishes somewhat as the surface forcing is reduced. Over the cold tongue there is very weak turbulence, mainly associated with the nearsurface shear layer and with longwave radiative cooling from patchy clouds atop the ABL. Convective surface mixed-layer turbulence causes the largest $\overline{w^{\prime 2}}$ in the mean because it is observed on all flights. At $4^{\circ} \mathrm{N}$ several of the flights observed a secondary maximum in turbulence in the cloud layer around $1 \mathrm{~km}$, which appears decoupled from the surface mixed layer. The turbulence at $12^{\circ} \mathrm{N}, 1.3 \mathrm{~km}$ is due to a cumulonimbus cloud sampled on one particular flight (9 October).

Between $1^{\circ} \mathrm{S}$ and $4^{\circ} \mathrm{N}$, the boundary layer inversion is easily discernible in the C-130 aircraft profile data. The circles in Fig. 10a represent the height and latitude at which the C-130 flew through the boundary layer inversion base. The inversion base height $z_{\text {inv }}$ was selected by inspection of each profile, as the height of local minimum in temperature just below where the potential temperature increases rapidly with height. For many profiles the inversion base was collocated with the boundary layer cloud top. The potential tem-

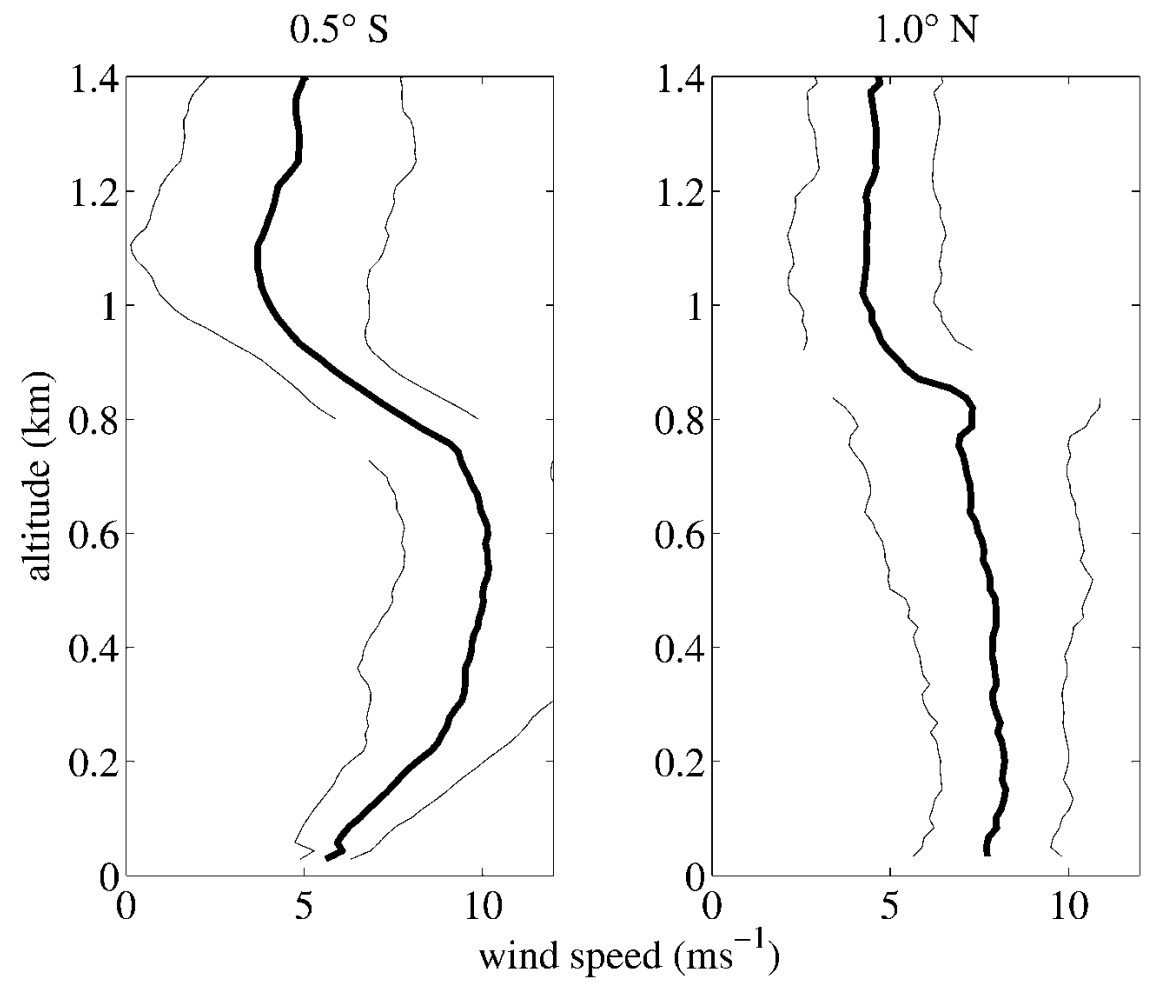

FIG. 9. Profiles of mean wind speed $\sqrt{u^{2}+v^{2}}$ at $0.5^{\circ} \mathrm{S}$ and $1^{\circ} \mathrm{N}$ for the eight $95^{\circ} \mathrm{W}$ flights. The vertical coordinate is normalized and translated before averaging as in Fig. 8. The thin lines denote the standard deviations about the observations. 
(a)

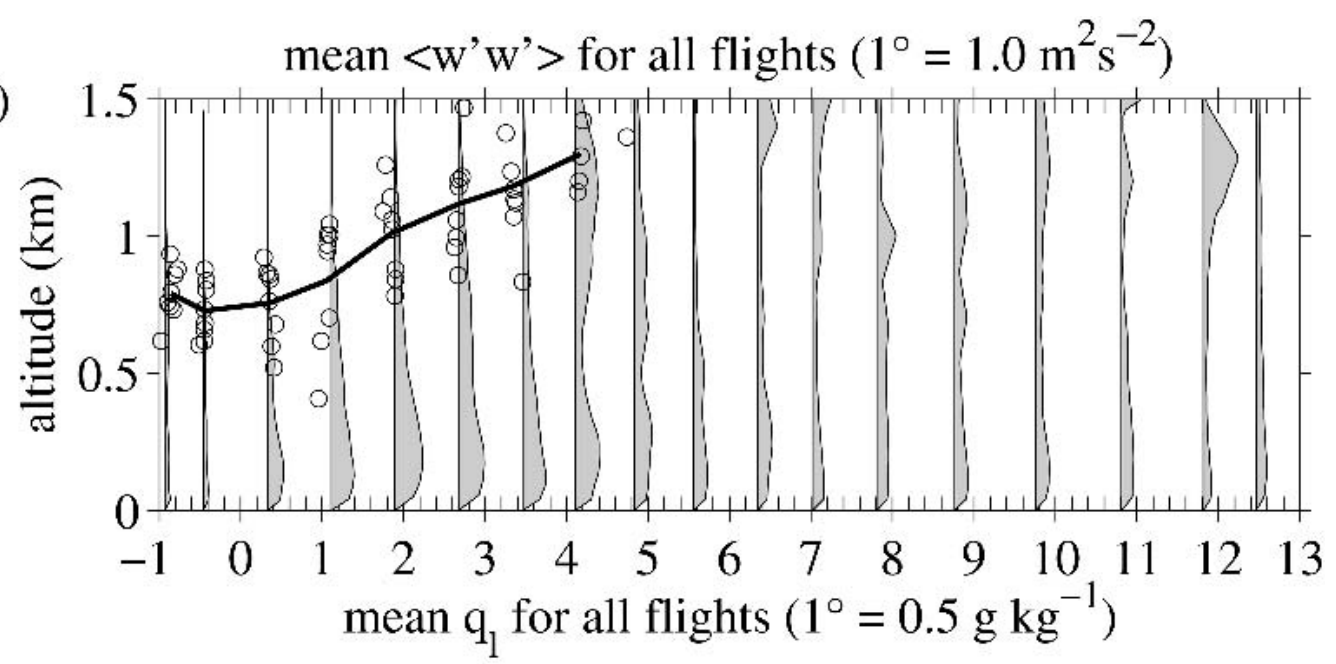

(b)

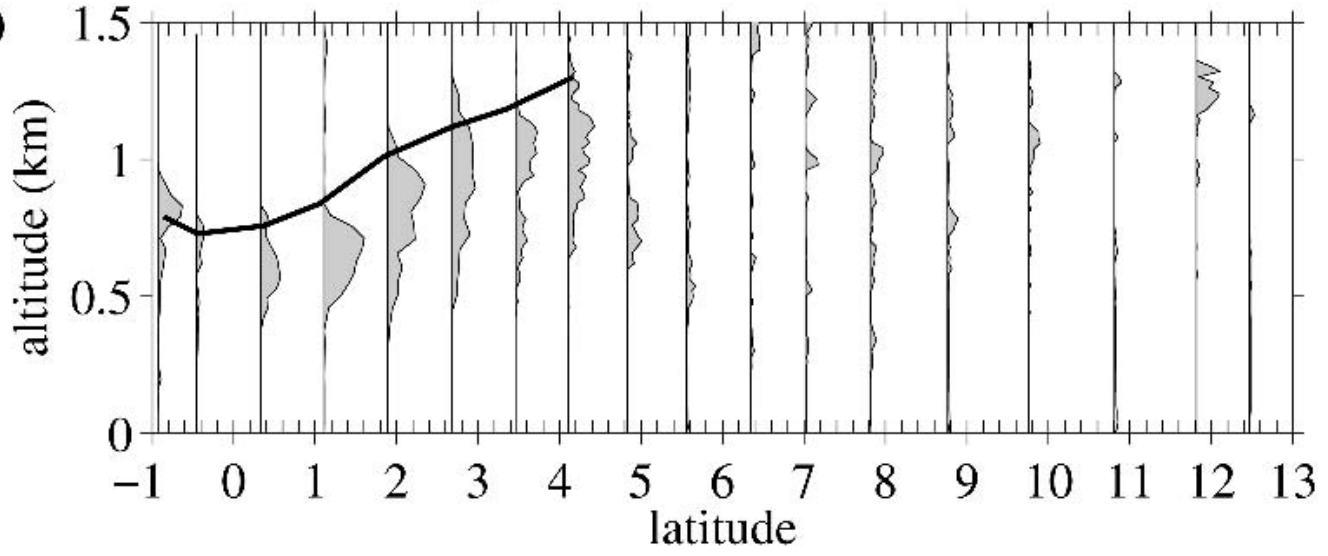

FIG. 10. Mean C-130 aircraft profiles of (a) turbulent vertical velocity variance $w^{\prime 2}$ and (b) cloud liquid water. The vertical coordinate was normalized to the inversion height south of $3.5^{\circ} \mathrm{N}$ to preserve the vertical structure in the mean. The thick line from $1^{\circ} \mathrm{S}$ to $4^{\circ} \mathrm{N}$ is the mean inversion base height over the eight flights. The circles in (a) are the locations when the $\mathrm{C}-130$ flew through the inversion base.

perature structure above the inversion base was not a discontinuity in potential temperature but a $3-5-\mathrm{K}$ increase in potential temperature over a layer of 50300-m depth. Inversion base heights determined in situ from the C-130 agreed with dropsonde inversion base heights and lidar backscatter cloud-top heights from the corresponding return leg 1-3 h later.

The mean inversion base height $z_{\text {inv }}$ (indicated by the thick lines in Figs. 10a and 10b) decreased northward over the cold tongue, south of the equator. Though the mean tendency was for the inversion to rise weakly between $0.4^{\circ} \mathrm{S}$ and $0.3^{\circ} \mathrm{N}$, half of the flights show the inversion continuing to shallow in this transitional regime. North of $0.3^{\circ} \mathrm{N}$ the inversion rose at a rate of 1.3 $\mathrm{m} \mathrm{km}{ }^{-1}$ northward. At no latitude did the inversion height have an obvious temporal trend over the eight flights.

We can use the downstream-deepening rate of the inversion height to deduce the mean entrainment rate $w_{e}$. Averaging over time and neglecting zonal advection,

$$
V \frac{\partial z_{\text {inv }}}{\partial y}=\bar{w}+w_{e}
$$

The ABL-mean meridional wind $V$ advecting the ABL inversion height in (8) was calculated between $0.3^{\circ}$ and $4^{\circ} \mathrm{N}$ for each flight by vertically averaging from $30 \mathrm{~m}$ to the base of the inversion. We assumed a subsidence rate $-\bar{w}=4 \pm 2 \mathrm{~mm} \mathrm{~s}^{-1}$ based on September-October 2001 National Centers for Environmental Prediction (NCEP) reanalyses at $850 \mathrm{hPa}, 2.5^{\circ} \mathrm{N}$ (Kistler et al. 2001). Our estimated uncertainty in the subsidence velocity is due to the large gradient of the subsidence velocity between the equator and the ITCZ, which is not well resolved in the reanalysis, and potential systematic biases in the reanalysis. The entrainment rate averaged over all flights was $w_{e}=14 \pm 3 \mathrm{~mm} \mathrm{~s}^{-1}$. The average entrainment rate over all the flights was heavily influenced by the entrainment rate estimate for RF14 on 2 October, which was $28 \mathrm{~mm} \mathrm{~s}^{-1}$, more than twice as large as any of the other estimates. Conditions on 2 October had been affected by a southward propagating 
disturbance. Excluding this outlier, the average entrainment rate was $w_{e}=12 \pm 2 \mathrm{~mm} \mathrm{~s}^{-1}$. This value is larger than, but consistent with, a similar calculation by Wood and Bretherton (2004), which uses satellite observations to deduce the average inversion height in a $2.5^{\circ} \times$ $2.5^{\circ}$ box. Their estimate involves more horizontal and time averaging, so it can be expected to smear out the sharp peak in $w_{e}$ north of the sharp SST front.

The entrainment rate inferred from the rise rate of the ABL inversion is much larger than can be explained by surface-buoyancy-driven turbulence alone. For a surface-driven mixed layer, the turbulence is proportional to the convective velocity scale

$$
w_{*}=(h B)^{1 / 3},
$$

where $h$ is the surface mixed-layer depth, estimated as $600 \mathrm{~m}$ from the top of the apparent mixed layer in Fig. $10 \mathrm{a}$ and $B$ is the surface buoyancy flux defined in (7). From Fig. 4, we estimate the buoyancy flux to be $1.2 \times$ $10^{-3} \mathrm{~m}^{2} \mathrm{~s}^{-3}$. The convective velocity scale $w_{*}$ is related by a mixed-layer scaling to the vertical velocity variance [Garratt 1992, Eq. (3.109)],

$$
\overline{w^{\prime 2}}=\left[1.08 w_{*}(z / h)^{1 / 3}(1-z / h)^{1 / 3}\right]^{2},
$$

which has a maximum vertical velocity variance at $z / h$ $=1 / 2$. The maximum vertical velocity variance expected for the observed buoyancy flux is $\max _{z}\left(\overline{w^{\prime 2}}\right)=$ $0.38 \mathrm{~m}^{2} \mathrm{~s}^{-2}$, in agreement with the maximum mean $\overline{w^{\prime 2}}$ shown in Fig. 10 at $2^{\circ} \mathrm{N}$. Thus, the subcloud turbulence has an intensity consistent with its being driven by the surface buoyancy flux. However, the entrainment rate is larger than would be predicted from the surface flux alone. For a dry convective mixed layer the entrainment rate $w_{e}$ scales as

$$
w_{e}=\frac{0.2 B}{\Delta b}=\frac{0.2 w_{* 3}}{h \Delta b},
$$

where $\Delta b=g \Delta \theta_{v} / \theta_{v}$ is the buoyancy jump capping the inversion. For the values at $2^{\circ} \mathrm{N}$, and an inversion strength $\Delta \theta_{v}=3 \mathrm{~K}, w_{e}$ would be $2.5 \mathrm{~mm} \mathrm{~s}^{-1}$. The surface mixed-layer scaling greatly underestimates the observed entrainment velocity $w_{e}$. We do not fully understand why the observed entrainment is so much greater than this scaling would suggest, but two possible reasons are 1) additional turbulence is generated at the top of the boundary layer, either by latent heating in clouds, radiative cooling at the cloud tops, or vertical wind shear causing Kelvin-Helmholtz instabilities and 2) the capping inversion is distributed over a layer a few hundred meters thick, rather than being a discontinuous jump in potential temperature. Because the inversion is distributed over a deep layer, the observed entrainment velocity effectively entrains air into the boundary layer from an intermediate transition layer, rather than air truly characteristic of the free troposphere.

\section{c. Cloud observations}

Figure 11 shows visible images from the GOES-8 satellite from $10^{\circ} \mathrm{S}$ to $12^{\circ} \mathrm{N}, 96.5^{\circ}$ to $93.5^{\circ} \mathrm{W}$ for the times of the eight flights. The images chosen were those with full spatial coverage nearest 1845 UTC in time. On the afternoon of 9 October, none of the images had coverage south of the equator, and the 1845 UTC image was chosen. Although the images vary from day to day, some persistent features are noteworthy. Stratocumulus, organized in $50-\mathrm{km}$ cells, was visible south of the equator. The stratocumulus clouds were optically thin and reduced in fraction toward the equator. The $20^{\circ} \mathrm{C}$ isotherm, denoted in Fig. 11 by the thick gray lines, indicates the location of the cold tongue. Over the cold tongue there was a minimum in cloud fraction. Scattered ABL stratocumuli were often present but appear thinner and less organized than the stratocumulus south of the cold tongue, indicating that decoupling between the cloud layer and the subcloud mixed layer might be occurring over the cold tongue. Thin altostratus clouds above the boundary layer were seen occasionally over the cold tongue. The highest cloud fraction on average was in the stratocumulus region between $1^{\circ}$ and $3^{\circ} \mathrm{N}$. The location of the cloud maximum could be visibly displaced north or south, corresponding to the meridional displacement of the SST front. The $20^{\circ} \mathrm{C}$ isotherm near the equator showed the location of the SST front. Within $1^{\circ}$ of the cold tongue, the stratocumulus typically showed little organization on scales exceeding 10 $\mathrm{km}$. The stratocumulus between $1^{\circ}$ and $3^{\circ} \mathrm{N}$ lay over the lower-ABL convective mixed layer (as shown in Fig. 10). Cloud fraction decreased farther north as clouds became organized into roll structures with widths of about $20 \mathrm{~km}$, oriented slightly to the right of the mean wind direction. ITCZ deep convection occurred between $8^{\circ}$ and $12^{\circ} \mathrm{N}$. It was highly variable and randomly sampled by the $95^{\circ} \mathrm{W}$ flights, as seen in the images of Fig. 11.

Figure $10 \mathrm{~b}$ shows the mean vertical structure of cloud liquid water content. South of the equator stratocumulus clouds were observed near the inversion base, well above the top of the stable near-surface shear-driven layer. These clouds were presumably cut off from a local moisture source. Following de Szoeke and Bretherton (2004), we interpret these as residual stratocumulus maintained by cloud-top radiative cooling and entraining into relatively moist above-inversion conditions. A minimum in cloudiness occurred at $0.4^{\circ} \mathrm{S}$, the typical northernmost extent of stratocumulus clouds surviving over the cold water. North of the SST front the clouds contributing most to the mean liquid water content were the stratocumulus above the surface-driven convective mixed layer. The SST front moved between the equator and $1^{\circ} \mathrm{N}$. During some flights, the cold tongue extended to $0.3^{\circ} \mathrm{N}$, so the cloudiness here was transitional between the cold and warm SST regimes. Above the convective mixed layer 

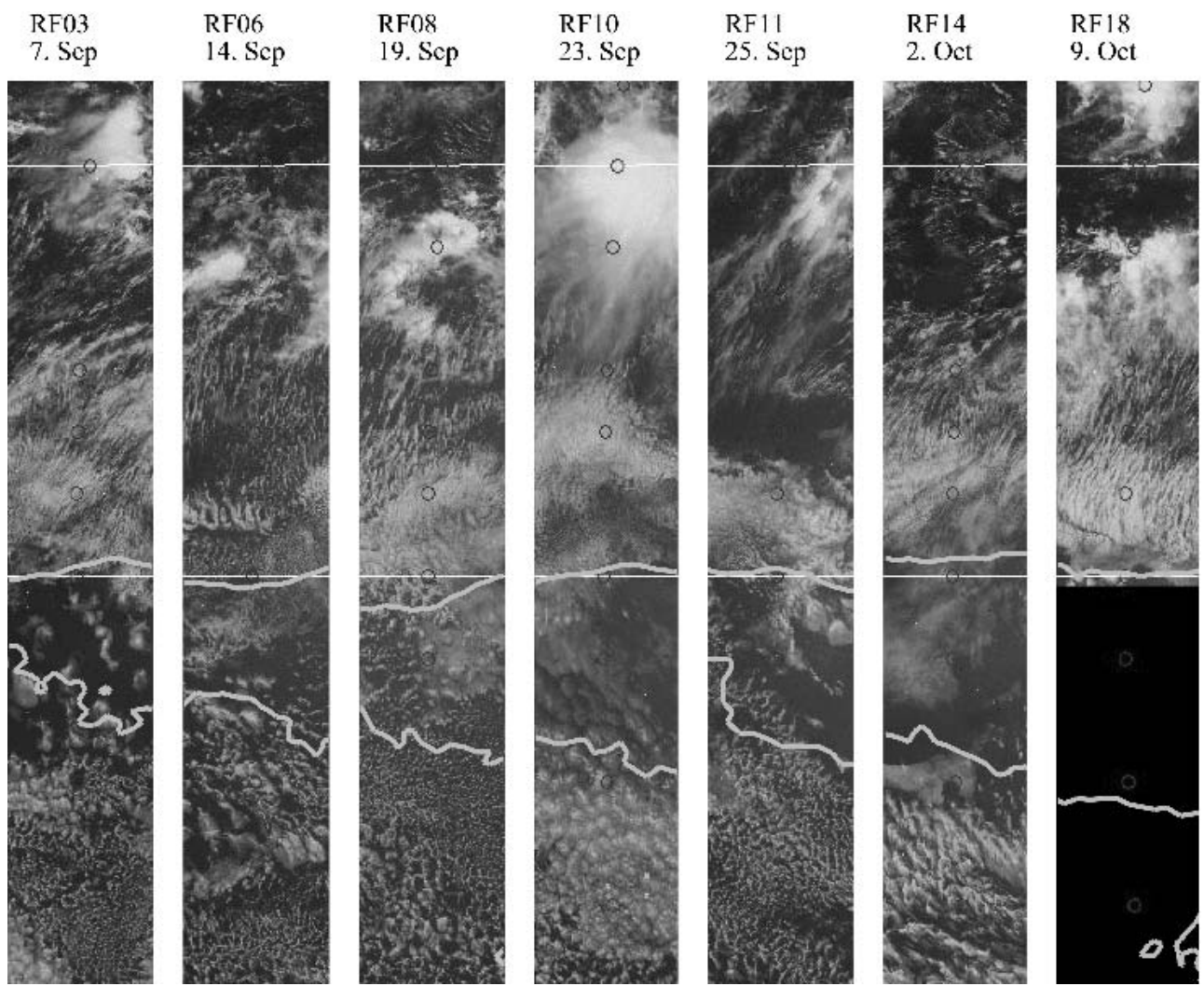

RF19 10. Oet

FIG. 11. GOES-8 channel-1 satellite images show reflection of visible solar radiation by clouds. Strips from $10^{\circ} \mathrm{S}$ to $12^{\circ} \mathrm{N}$ along $95^{\circ} \mathrm{W}$ are shown for the days of the C-130 EPIC $200195^{\circ} \mathrm{W}$ flights. The GOES-8 image with full coverage nearest to 1845 UTC of the flight date is shown. The thick superimposed lines are $20^{\circ} \mathrm{C} \mathrm{SST}$ isotherms.

cloud base was approximately $500 \mathrm{~m}$, and cloud tops rose from $800 \mathrm{~m}$ at $0.3^{\circ} \mathrm{N}$ to $1400 \mathrm{~m}$ at $4^{\circ} \mathrm{N}$. Sporadic shallow cumuli with bases sometimes lower than $500 \mathrm{~m}$ and tops often higher than $1500 \mathrm{~m}$ were observed in the warm pool region north of $5^{\circ} \mathrm{N}$.

Lidar and radiometric observations from the C-130 aircraft provide further information about the clouds along $95^{\circ} \mathrm{W}$. Figure $12 \mathrm{a}$ shows the low cloud fraction estimated by lidar as the C-130 flew from $0.5^{\circ}$ to $12^{\circ} \mathrm{N}$ during the return ferry. The low cloud fraction in each $0.2^{\circ}$ latitude bin is shown for each flight. The median cloud fraction for all flights is also shown. There is a decreasing trend in median cloud fraction with latitude from near unity between $0.5^{\circ}$ and $2^{\circ} \mathrm{N}$ to near zero north of $7^{\circ} \mathrm{N}$, indicating a transition from dense stratocumulus to scattered shallow cumulus.

Figure 12b shows the albedo (ratio of leg mean upwelling to downwelling shortwave radiation) measured by the shortwave radiometers during the 1600-m C-130 legs. The symbols are the average albedo for the 1600-m legs for each flight; the dark line is their median. The median albedo increased from the equator to $3^{\circ}$ N. Since the cloud fraction actually decreased between $1.5^{\circ}$ and $3^{\circ} \mathrm{N}$, the albedo increase must be due to

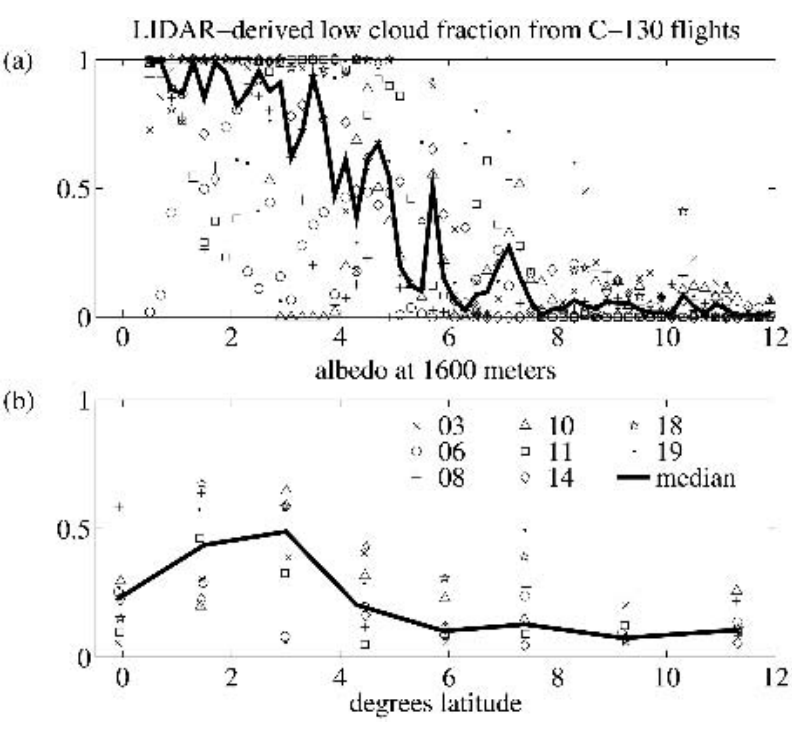

FIG. 12. (a) The low cloud fraction (cloud tops at 50-1500-m altitude) from lidar backscatter in $0.2^{\circ}$ latitude intervals, for each flight (symbols) and the median of all flights (line). (b) Albedo from the C-130 1-Hz data during each 1600-m leg (symbols) and the median over all flights (line). 
thickening of the clouds. The transition to lower albedo between $3^{\circ}$ and $5^{\circ} \mathrm{N}$ was quite rapid. The $1600-\mathrm{m}$ median albedo north of $5^{\circ} \mathrm{N}$ was less than 0.2 .

Few of these clouds produced measurable rainfall. The average precipitation during September-October 2001 from TAO buoys is shown in Fig. 13. The precipitation by the ABL clouds south of $4^{\circ} \mathrm{N}$ was zero. The maximum rainfall of $15 \mathrm{~mm}$ day $^{-1}$ was found at $8^{\circ} \mathrm{N}$, in the ITCZ. In the flanks of the ITCZ at $5^{\circ}$ and $12^{\circ} \mathrm{N}$ the rain rate dropped markedly to 1 and $3 \mathrm{~mm} \mathrm{day}^{-1}$, respectively. The skewness of the rainfall distribution is reflected by the asymmetry of the quartiles, indicated by the vertical bars in Fig. 13.

\section{Thermodynamic budgets}

From the data collected in situ by the C-130 we can form heat and moisture budgets of the ABL between $0^{\circ}$ and $3^{\circ} \mathrm{N}$ and estimate the net energy and freshwater fluxes into the ocean. These budget calculations illuminate the ABL physics and atmosphere-ocean feedbacks and can be used to validate numerical weather prediction and climate model simulations.

\section{a. Water budget}

The total water budget for the $\mathrm{ABL}$ along $95^{\circ} \mathrm{W}$ south of the ITCZ consists of a balance of dry advection, moistening through evaporation at the surface $F_{\text {sfc }}^{q}$, and entrainment of dry air at the top of the ABL $F_{\text {entr. }}^{q}$. Precipitation from $0^{\circ}$ to $4^{\circ} \mathrm{N}$ from TAO buoy measurements for September-October 2001 is negligible (Fig. 13). Storage averaged over two months is also negligible. De Szoeke and Bretherton (2004) estimate zonal advection of latent and sensible heat from NCEP reanalysis to be -5 and $-1 \mathrm{~W} \mathrm{~m}^{-2}$. Since these are within the estimation errors of the dominant budget terms, zonal advection will be neglected henceforth. With these approximations, we phrase the moisture budget in energy units as a "latent heat" budget,

$$
L \int_{0}^{z_{\text {inv }}} \rho v \frac{\partial q_{t}}{\partial y} d z=F_{\mathrm{sfc}}^{q}+F_{\mathrm{entr}}^{q} .
$$

The left-hand side is the ABL mean meridional advection of total-water specific humidity $q_{t}$. Since this is a

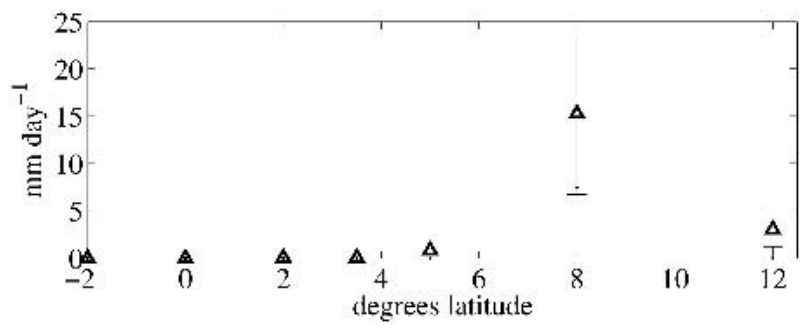

FIG. 13. Mean precipitation (triangles) from the TAO buoys for Sep-Oct 2001. The median precipitation (dots) and first and third quartiles (vertical bars) are also shown. bulk budget for a mixed boundary layer, we only computed it where a capping inversion could be identified. The height of the inversion was defined to be that indicated by the black line in Fig. 10. The C-130 ascent and descent profile data were gridded to $20-\mathrm{m}$ vertical intervals. The advection of specific humidity was calculated at the location of the $30-\mathrm{m}$ legs at $0.7^{\circ}$ and $2.2^{\circ} \mathrm{N}$ by averaging the density $\rho$ and meridional velocity $v$ from the flanking ascent and descent profiles at all grid levels. The gradient of specific humidity $\partial q_{t} / \partial y$ was computed with a centered difference from the flanking profiles. The vertical integral was formed by summing these quantities at levels beneath the inversion height $z_{\text {inv }}$. Thus, the advection was collocated with the bulk surface fluxes derived from the $30-\mathrm{m}$ legs at $0.7^{\circ}$ and $2.2^{\circ} \mathrm{N}$. The standard errors in the eight-flight mean budget terms are averaged over the two latitudes,

$$
\epsilon=\left[\left(\sigma_{0.7}^{2}+\sigma_{2.2}^{2}\right) / 2(N-1)\right]^{1 / 2},
$$

where

$$
\sigma^{2}=\sum_{n=1}^{N} Q^{\prime 2} /(N-1)
$$

is the variance of the quantity $Q$ expected in a mean of all $N=8$ flights.

Table 2 summarizes the latent heat budget at $0.7^{\circ}$ and $2.2^{\circ} \mathrm{N}$, with the entrainment flux calculated as a residual. Calculating the entrainment flux as a residual enables us to compare entrainment rates among the different budgets. Budget terms were also calculated at $3.8^{\circ} \mathrm{N}$, but were inaccurate because the inversion is often either difficult to identify or higher than the top of the profile legs near $4^{\circ} \mathrm{N}$. The dominant balance of the moisture budget is between dry advection from the south and evaporation from the surface (each order 100 $\mathrm{W} \mathrm{m}^{-2}$ ). The implied entrainment drying is small (40 W $\mathrm{m}^{-2}$ ) and is on the order of its standard error, most of which is contributed by the uncertainty in the estimate of the meridional advection of moisture. The entrainment flux $F_{\text {entr }}^{q}$ is parameterized as bulk entrainment across a specific humidity jump of $\Delta q_{t}$ at the inversion,

TABLE 2. Terms in the water budget at $0.7^{\circ}$ and $2.2^{\circ} \mathrm{N}$. The entrainment flux $F_{\text {entr }}^{q}$ is calculated as a residual, and the entrain-

\begin{tabular}{|c|c|c|c|c|c|}
\hline Latitude & $-L$ & $\int_{0}^{z_{\text {inv }}} \rho v \frac{\partial q_{t}}{\partial y} d z$ & $F_{\mathrm{sfc}}^{q}$ & $F_{\text {entr }}^{q}$ & $w_{e}^{q}$ \\
\hline$\left({ }^{\circ} \mathrm{N}\right)$ & \multicolumn{4}{|c|}{$\left(\mathrm{W} \mathrm{m}^{-2}\right)$} & $\left(\mathrm{mm} \mathrm{s}^{-1}\right)$ \\
\hline 0.7 & & $-72 \pm 29$ & $116 \pm 15$ & $-44 \pm 33$ & $17 \pm 14$ \\
\hline 2.2 & & -154 & 183 & -29 & $12 \pm 14$ \\
\hline
\end{tabular}
ment rate $w_{\mathrm{e}}^{q}$ is calculated from the entrainment flux. Confidence bounds apply to both latitudes. 


$$
F_{\text {entr }}^{q}=\rho\left(z_{\text {inv }}\right) L\left(\Delta q_{t}\right) w_{e}^{q} .
$$

The specific humidity jump was $\Delta q_{t}=-0.9 \pm 0.3 \mathrm{~g}$ $\mathrm{kg}^{-1}$, calculated as the average difference between the specific humidity $50 \mathrm{~m}$ above and below the inversion. This jump is small due to the high free-tropospheric humidity above the ABL. We estimate the entrainment rate $w_{e}^{q}$ from the bulk formula (15). The confidence intervals of the entrainment rate estimates shown in Table 2 are very broad but overlap the mean entrainment rate derived from the ABL downstream deepening (12 $\pm 2 \mathrm{~mm} \mathrm{~s}^{-1}$, section $\left.3 \mathrm{~b}\right)$. The water budget does not tightly constrain the entrainment rate because entrainment of moisture into the ABL is a small residual compared to moisture advection and surface evaporation.

\section{b. Heat budget}

Using the surface and radiative fluxes from section $3 \mathrm{a}$ and the appendix, a heat budget can also be constructed for the ABL. Neglecting zonal advection, storage, and, precipitation effects as before we obtain

$$
C_{P} \int_{0}^{z_{\text {inv }}} \rho v \frac{\partial T_{l}}{\partial y} d z=F_{\text {sfc }}^{T}-\left[F_{\text {rad }}\right]_{0}^{z_{\text {inv }}}+F_{\text {entr }}^{T}
$$

The left-hand side is the advection of liquid water temperature $T_{l}=T-L q_{l} / C_{P}$, which accounts for the heating due to condensation and evaporation of water. In the appendix, we use the aircraft observations to estimate the net radiative flux divergence $\left[F_{\text {rad }}\right]_{0}^{\text {zinv }}$ due to both shortwave and longwave contributions and its observational uncertainty. The surface sensible heat flux is $F_{\text {sfc. }}^{T}$. Table 3 summarizes the terms in the heat budget. In the $0^{\circ}-3^{\circ} \mathrm{N}$ heat budget, cold advection and radiative cooling were balanced by surface heat flux and entrainment warming. Advective cooling, surface heating, radiative cooling, and entrainment heating are all of comparable magnitude in the heat budget, advective cooling being about $50 \%$ larger than the surface flux.

The entrainment heat flux can also be used to estimate a bulk entrainment rate $w_{e}^{T}$ :

$$
F_{\text {entr }}^{T}=\rho\left(z_{\text {inv }}\right) C_{P} \Pi\left(z_{\text {inv }}\right)\left(\Delta \theta_{l}\right) w_{e}^{T} .
$$

From the soundings we estimated the jump in the liquid water potential temperature to be $\Delta \theta_{l}=2.6 \pm 0.5 \mathrm{~K}$ at both latitudes, yielding entrainment estimates $w_{e}^{T}$ (Table 3) consistent with the entrainment estimated from the downstream deepening of the inversion (12 \pm $2 \mathrm{~mm} \mathrm{~s}^{-1}$ ).

\section{c. Forcings on the upper ocean}

Radiation absorbed by the sea surface, and surface latent and sensible heat fluxes are important to the upper-ocean heat budget. Figure 14 shows the combined radiative, latent, and sensible heat flux into the ocean (positive downward), as observed by the TAO buoys and from the $30-\mathrm{m}$ legs by the C- 130 . At $2^{\circ}, 3.5^{\circ}$, and $5^{\circ} \mathrm{N}$ the latent heat fluxes are about $40 \mathrm{~W} \mathrm{~m}^{-2}$ more positive for the TAO data than for the C-130 eddy correlation fluxes (cf. Fig. 4). At $10^{\circ}$ and $12^{\circ} \mathrm{N}$ the net radiative flux is at least $50 \mathrm{~W} \mathrm{~m}^{-2}$ more positive for the TAO data. The more positive heat fluxes into the ocean in the TAO data can be attributed to the latent and net radiative heat fluxes. Sampling different cloud conditions could be partly responsible for the large differences in the radiative fluxes in the ITCZ. The vertical bars show the standard deviations of the total heat fluxes. The forcing by the atmosphere on the upperocean heat budget is strongly frontolytic, heating the ocean surface $150 \mathrm{~W} \mathrm{~m}^{-2}$ over the cold tongue and cooling it $50 \mathrm{~W} \mathrm{~m}^{-2}$ between $2^{\circ}$ and $4^{\circ} \mathrm{N}$ where the ocean surface is warm. Assuming a 40-m-deep ocean mixed layer with no advection or mixing at its base, the heating by the atmosphere would be able to remove the existing SST gradient in just two months.

\section{Conclusions}

The EPIC $200195^{\circ} \mathrm{W}$ flights provide a suite of observations of the northward cross-equatorial and ITCZ inflow atmospheric boundary layer. Surface observations from the $30-\mathrm{m}$ flight legs supplement the observations from the TAO buoys along $95^{\circ} \mathrm{W}$. The eight C-130 flights sampled the variability well enough to characterize the mean during the EPIC intensive observation period. Surface sensible and latent heat fluxes were near zero over the cold tongue and quite large (20 $\mathrm{W} \mathrm{m}{ }^{-2}$ for sensible, $150 \mathrm{~W} \mathrm{~m}^{-2}$ for latent heat flux) between the equator and $5^{\circ} \mathrm{N}$. A sudden increase in the meridional wind stress was also observed across the SST front between the cold tongue and the warmer water to the north, consistent with scatterometer observations. Over the cold tongue surface winds were

TABLE 3. Terms in the heat budget at $0.7^{\circ}$ and $2.2^{\circ} \mathrm{N}$. The entrainment flux $F_{\text {entr }}^{T}$ is calculated as a residual, and the entrainment rate

\begin{tabular}{|c|c|c|c|c|c|}
\hline Latitude & $-C_{P} \int_{0}^{z_{\text {inv }}} \rho v \frac{\partial T_{l}}{\partial y} d z$ & $F_{\mathrm{sfc}}^{T}$ & $F_{\text {rad }}$ & $F_{\text {entr }}^{T}$ & $w_{e}^{T}$ \\
\hline$\left({ }^{\circ} \mathrm{N}\right)$ & \multicolumn{4}{|c|}{$\left(\mathrm{W} \mathrm{m}^{-2}\right)$} & $\left(\mathrm{mm} \mathrm{s}^{-1}\right)$ \\
\hline 0.7 & $-30 \pm 7$ & $18 \pm 3$ & $-20 \pm 8$ & $31 \pm 11$ & $11 \pm 4$ \\
\hline 2.2 & -47 & 29 & $-26 \pm 11$ & $45 \pm 13$ & $16 \pm 6$ \\
\hline
\end{tabular}
$w_{e}^{T}$ is calculated from the entrainment flux. Confidence bounds on the advection and surface forcing apply at both latitudes. Confidence bounds on the radiative forcing include the upper and lower bound on the net radiative cooling estimates. 


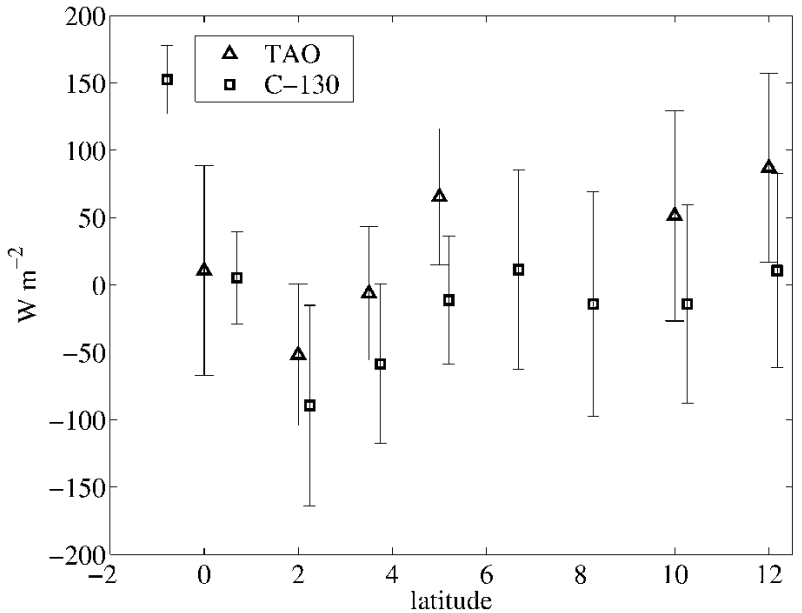

FIG. 14. Combined radiative, latent, and sensible heat flux into the ocean estimated from TAO observations (triangles) and C-130 observations (squares). Standard deviations are indicated by the vertical bars.

weak with a weakly turbulent stratified shear layer in the lowest $200 \mathrm{~m}$ and a meridional jet at about $500 \mathrm{~m}$. The mean structure of the ABL wind observed across the SST front north of the cold tongue was generally anticipated by Wallace et al. (1989).

Over the cold tongue skies were often clear, sometimes overlain by patchy thin stratus cloud. North of the cold tongue strong surface buoyancy fluxes drove vigorous convection and formation of a persistent stratocumulus layer that rapidly deepened to the north due to its high entrainment rate, estimated at $12 \pm 2 \mathrm{~mm} \mathrm{~s}^{-1}$ between the equator and $3^{\circ} \mathrm{N}$. As the $\mathrm{ABL}$ deepened from $2^{\circ}$ to $4^{\circ} \mathrm{N}$, it quickly developed a "cumulus coupled" structure with a distinct subcloud mixed layer and overlying layer of shallow cumulus rising into stratocumulus.

The types and horizontal scales of clouds were identified from satellite observations. Stratocumulus typically were organized on the mesoscale south of the cold tongue. They partially cleared over the cold tongue, then reformed into an overcast sheet of unorganized or small-celled stratocumulus north of the warm SST front. Streets of stratocumulus were often seen aligned nearly parallel to the low-level wind. Farther north stratocumulus dissipate as the shallow cumulus deepen. Almost no precipitation is observed south of $5^{\circ} \mathrm{N}$. At $5^{\circ} \mathrm{N}$ congestus and cumulonimbus convection start to develop. The satellite pictures and TAO observations show that the general south-to-north structure of the boundary layer does not change dramatically from day to day. Aircraft and satellite observations show maximum cloudiness between the equator and $3^{\circ} \mathrm{N}$.

ABL heat and moisture budgets were computed for $0^{\circ}-3^{\circ} \mathrm{N}$. In the moisture budget the dominant balance is between dry advection and surface evaporation with slight residual entrainment drying. In the heat budget cold advection, entrainment warming, surface heating, and radiative cooling are all of comparable importance. Entrainment rates, estimated independently as residuals from each budget, had large uncertainties but were compatible with the above estimate from the deepening of the ABL with latitude.

Cloud and radiation feedbacks seem to play a significant role in the ABL evolution. This is demonstrated by the heat budget - radiative cooling at ABL cloud tops is on the order of the surface heating, contributing perhaps half as much buoyancy flux as the surface. The importance of clouds in driving the ABL circulations is also demonstrated by using standard formulas for convection forced only by surface buoyancy flux. The entrainment rate is far too large to be explained by surface buoyancy flux alone.

The net surface heat flux is $150 \mathrm{~W} \mathrm{~m}^{-2}$ into the ocean over the cold tongue and at least $50 \mathrm{~W} \mathrm{~m}^{-2}$ out of the ocean at $2^{\circ}-4^{\circ} \mathrm{N}$. Ocean processes must be very active to maintain the observed $7^{\circ} \mathrm{C} \mathrm{SST}$ front despite the effect of this strong opposing heat flux gradient.

The EPIC 2001 observations quantify the interplay of surface forcing, turbulence, winds, and clouds. The representation of the cross-equatorial flow by large-scale models can be compared with this dataset. EPIC 2001 provides observational evidence to test model representations of the response of the ABL to the SST, the rapid entrainment by the cloud-topped cold-advection boundary layer, and the transition to a cumuluscoupled boundary layer.

Acknowledgments. We thank the NCAR Research Aviation Facility, the TAO office, and the crew and scientists aboard the Ronald H. Brown for providing observational data for the EPIC project. We acknowledge support from NSF Grants ATM-0082384 and ATM-0082391.

\section{APPENDIX}

\section{Radiative Flux Calculations}

For an ABL budget, we need the diurnally averaged ABL radiative flux divergence $\left[F_{\text {rad }}\right]_{0}^{Z_{\text {inv }}}$. The 30 - and 1600-m aircraft legs provide instantaneous information on the radiative fluxes in the ABL. There are several complications in using these fluxes to estimate the radiative flux divergence $\left[F_{\text {rad }}\right]_{0}^{\text {zinv }}$. These include the dependence of the radiative fluxes on cloud cover and time of day, and the latitude-time staggering of the 30and $1600-\mathrm{m}$ legs. We estimate the longwave radiative cooling of the ABL based on the measured difference of net longwave radiative flux between 30 and $1600 \mathrm{~m}$ from the level legs. To correct for longwave flux divergence between the ABL top (inversion base) and 1600 $\mathrm{m}$, we use longwave radiation measurements from the $30-1600-\mathrm{m}$ profiles. From a $10-\mathrm{m}$ resolution, 18-band radiative transfer model calculation $(\mathrm{Fu}$ and Liou 1992), the estimated free-tropospheric longwave radia- 
tive flux divergence is $28 \mathrm{~W} \mathrm{~m}^{-2} \mathrm{~km}^{-1}$, so we reduce the 1600-m net longwave flux by

$$
A_{\text {IR }}=-28 \mathrm{~W} \mathrm{~m}^{-2} \mathrm{~km}^{-1}\left(1.6 \mathrm{~km}-z_{\text {inv }}\right)
$$

to get an ABL-top flux. This longwave flux divergence is consistent with that observed between the ABL top and $1600 \mathrm{~m}$ on the profiles taken during the eight flights. This adjustment was $5-15 \mathrm{~W} \mathrm{~m}^{-2}$ between $0^{\circ}$ and $4^{\circ} \mathrm{N}$. The longwave radiative divergence for the ABL (Fig. A1) is inferred from the difference between the net longwave flux at the inversion $z_{\text {inv }}$ and at $30 \mathrm{~m}$. Between the equator and $4^{\circ} \mathrm{N}$ the divergence was 30 to $40 \mathrm{~W} \mathrm{~m}^{-2}$. Profiles of the net longwave flux from the ascent and descent legs between the equator and $4^{\circ} \mathrm{N}$ suggest that most of this $30-40 \mathrm{~W} \mathrm{~m}^{-2}$ flux divergence occurred in the top $200 \mathrm{~m}$ of the cloud layer, so the ABL-top cooling provides a buoyancy flux on the order of that of the surface buoyancy flux. This cloudtop buoyancy flux is probably instrumental in producing some of the turbulence in the cloud layer seen in Fig. 10a and in driving the entrainment rate higher than that predicted by the surface mixed-layer scaling in section $3 b$

The longwave radiative cooling is partly offset by the solar heating of the ABL. In a partly cloudy ABL, aircraft measurements of solar radiative flux convergence are notoriously difficult due to the different cloud fields sampled among legs. Nevertheless, we derived a daily average as follows: We normalized the measured shortwave flux on each 30- and 1600-m flight leg to a daily average value by multiplying by the ratio of the cosine of the solar zenith angle during the observation to the diurnally averaged cosine of the solar zenith angle. We adjusted the diurnally normalized net solar flux measured at $1600 \mathrm{~m}$ to $z_{\text {inv }}$ as in (A1) but with an assumed free-tropospheric solar flux convergence of

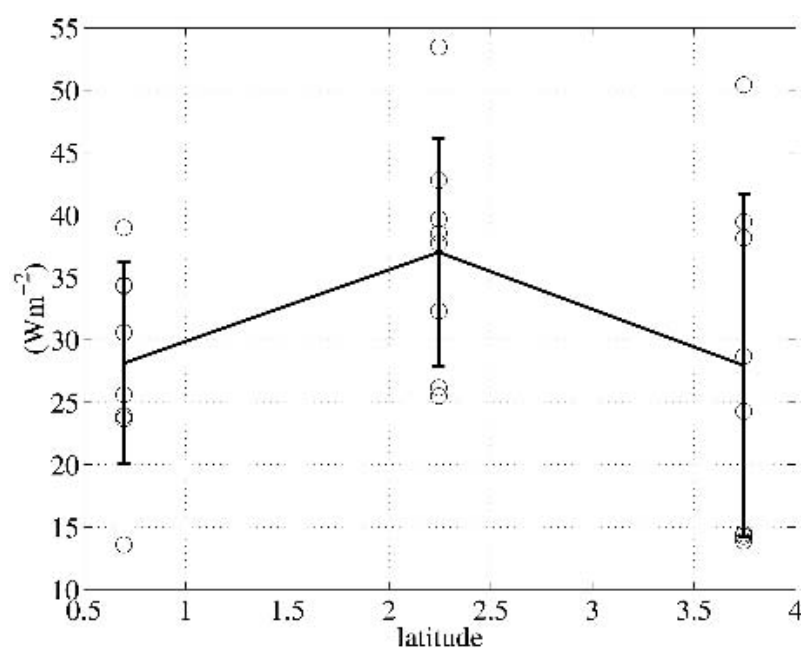

FIG. A1. Net longwave flux divergence for each leg (circles) and in the mean, with vertical bars denoting \pm 1 std dev (black line).

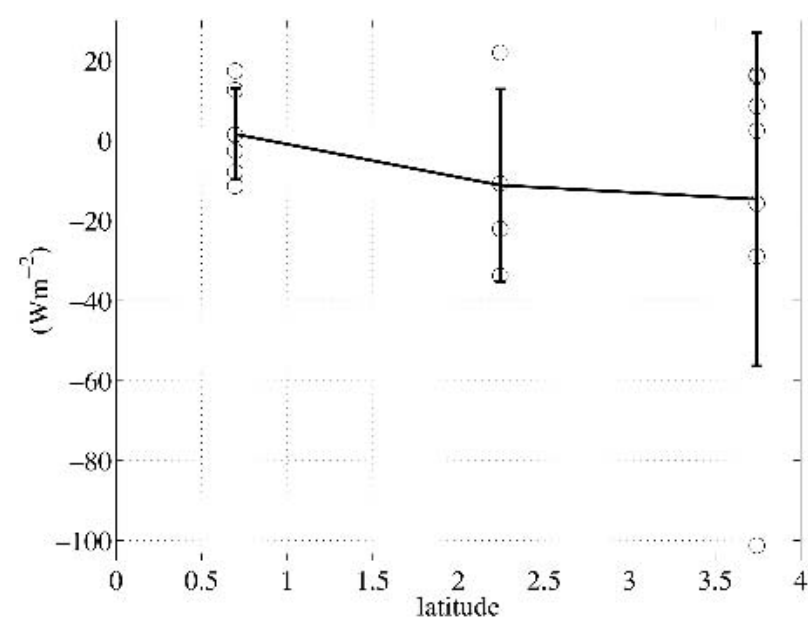

FIG. A2. Net diurnally averaged solar flux divergence for each leg (circles) and in the mean, with vertical bars denoting \pm 1 std dev (black line).

$7.5 \mathrm{~W} \mathrm{~m}^{-2} \mathrm{~km}^{-1}$, derived from the radiative transfer model. The resulting difference of 30-m and ABL-top net solar flux (Fig. A2) implies an eight-flight mean ABL flux convergence of approximately $10 \mathrm{~W} \mathrm{~m}^{-2}$ averaged over the three latitudes at which it was calculated. However, the interflight standard deviations indicated by the vertical bars in Fig. A2 are so large that even the sign of the flux difference cannot be inferred with any confidence. From these data, we can conclude only that the diurnally averaged ABL solar warming is somewhere between zero and the magnitude of the longwave radiative cooling. The diurnally averaged solar heating is on the order of $30 \%$ of the longwave radiative cooling, in accord with standard radiative transfer models applied to cloud-topped ABLs. Note that the EPIC $95^{\circ} \mathrm{W}$ flights are near to local noon when the net $\mathrm{ABL}$ radiative cooling is probably close to zero. This might be why we see little evidence of radiatively driven enhancement of $\overline{w^{\prime 2}}$ in the cloud layer, even in the persistent stratocumulus region at $1^{\circ}-3^{\circ} \mathrm{N}$.

\section{REFERENCES}

Bond, N. A., 1992: Observations of planetary boundary layer structure in the eastern equatorial Pacific. J. Climate, 5, 699706.

Chelton, D. B., and Coauthors, 2001: Observations of coupling between surface wind stress and sea surface temperature in the eastern tropical Pacific. J. Climate, 14, 1479-1498.

Contreras, R. F., 2002: Long-term observations of tropical instability waves. J. Phys. Oceanogr., 32, 2715-2722.

Cronin, M. F., N. A. Bond, C. Fairall, J. Hare, M. J. McPhaden, and R. A. Weller, 2002: Enhanced oceanic and atmospheric monitoring underway in eastern Pacific. Eos, Trans. Amer. Geophys. Union, 83, 210-211.

Deser, C., J. J. Bates, and S. Wahl, 1993: The influence of sea surface temperature gradients on stratiform cloudiness along the equatorial front in the Pacific Ocean. J. Climate, 6, 11721179. 
de Szoeke, S. P., and C. S. Bretherton, 2004: Quasi-Lagrangian large eddy simulations of cross-equatorial flow in the east Pacific atmospheric boundary layer. J. Atmos. Sci., 61, 18371858.

Fairall, C. W., E. F. Bradley, J. E. Hare, A. A. Grachev, and J. B. Edson, 2003: Bulk parameterization of air-sea fluxes: Updates and verification for the COARE algorithm. J. Climate, 16, 571-591.

Fu, Q., and K. N. Liou, 1992: On the correlated $k$-distribution method for radiative transfer in nonhomogeneous atmospheres. J. Atmos. Sci., 49, 2139-2156.

Garratt, J. R., 1992: The Atmospheric Boundary Layer. Cambridge University Press, $316 \mathrm{pp}$.

Johnson, G. C., B. M. Sloyan, W. S. Kessler, and K. E. McTaggart, 2002: Direct measurements of upper ocean currents and water properties across the tropical Pacific Ocean during the 1990s. Progress in Oceanography, Vol. 52, Pergamon Press, 31-61.

Kistler, R., and Coauthors, 2001: The NCEP-NCAR 50-year reanalysis: Monthly means CD-ROM and documentation. Bull. Amer. Meteor. Soc., 82, 247-267.

Klein, S. A., and D. L. Hartmann, 1993: The seasonal cycle of low stratiform clouds. J. Climate, 6, 1588-1606.

Legeckis, R., 1977: Long waves in the eastern equatorial Pacific Ocean: A view from a geostationary satellite. Science, 197, 1179-1181.

Lenschow, D. H., J. Mann, and L. Kristensen, 1994: How long is long enough when measuring fluxes and other turbulence statistics? J. Atmos. Oceanic Technol., 11, 661-673.

McGauley, M., C. Zhang, and N. Bond, 2004: Large-scale characteristics of the atmospheric boundary layer in the eastern Pacific cold tongue-ITCZ region. J. Climate, 17, 3907-3920.

Raymond, D. J., and Coauthors, 2004: EPIC2001 and the coupled ocean-atmosphere system of the tropical east Pacific. Bull. Amer. Meteor. Soc., 85, 1341-1354.

Wallace, J. M., T. P. Mitchell, and C. Deser, 1989: The influence of sea-surface temperature on surface wind in the eastern equatorial Pacific: Seasonal and interannual variability. $J$. Climate, 2, 1492-1499.

Wang, Y., S.-P. Xie, H. Xu, and B. Wang, 2004: Regional model simulations of marine boundary layer clouds over the southeast Pacific off South America. Part I: Control experiment. Mon. Wea. Rev., 132, 274-296.

Wood, R., and C. S. Bretherton, 2004: Boundary layer depth, entrainment, and decoupling in the cloud-capped subtropical and tropical marine boundary layer. J. Climate, 17, 35753587.

Yin, B. F., and B. A. Albrecht, 2000: Spatial variability of atmospheric boundary layer structure over the eastern equatorial Pacific. J. Climate, 13, 1574-1592.

Zeng, X., M. A. Brunke, M. Zhou, C. Fairall, N. A. Bond, and D. H. Lenschow, 2004: Marine atmospheric boundary layer height over the eastern Pacific: Data analysis and model evaluation. J. Climate, 17, 4159-4170. 